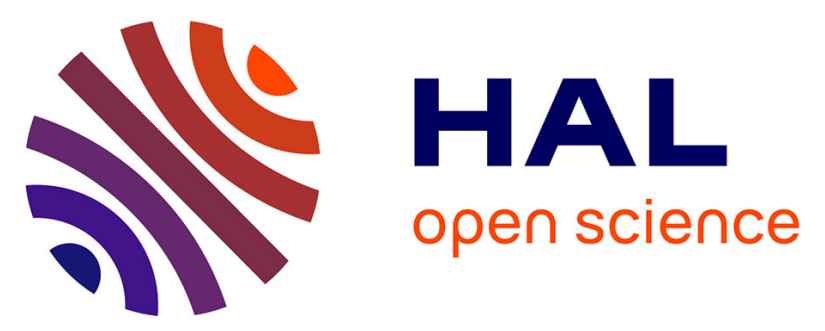

\title{
Tuning the Formation and Structure of the Silicon Electrode/Ionic Liquid Electrolyte Interphase in Superconcentrated Ionic Liquids
}

Khryslyn Arano, Srdan Begic, Fangfang Chen, Dmitrii Rakov, Driss Mazouzi, Nicolas Gautier, Robert Kerr, Bernard Lestriez, Jean Le Bideau, Patrick Howlett, et al.

\section{To cite this version:}

Khryslyn Arano, Srdan Begic, Fangfang Chen, Dmitrii Rakov, Driss Mazouzi, et al.. Tuning the Formation and Structure of the Silicon Electrode/Ionic Liquid Electrolyte Interphase in Superconcentrated Ionic Liquids. ACS Applied Materials \& Interfaces, 2021, 13 (24), pp.28281-28294. 10.1021/acsami.1c06465 . hal-03287950

\section{HAL Id: hal-03287950 https://hal.science/hal-03287950}

Submitted on 16 Jul 2021

HAL is a multi-disciplinary open access archive for the deposit and dissemination of scientific research documents, whether they are published or not. The documents may come from teaching and research institutions in France or abroad, or from public or private research centers.
L'archive ouverte pluridisciplinaire HAL, est destinée au dépôt et à la diffusion de documents scientifiques de niveau recherche, publiés ou non, émanant des établissements d'enseignement et de recherche français ou étrangers, des laboratoires publics ou privés. 


\section{Tuning the Formation and Structure of the Silicon}

\section{Electrode/Ionic Liquid Electrolyte Interphase in}

\section{Superconcentrated Ionic Liquids}

Khryslyn Araño,${ }^{\dagger \neq}{ }^{\ddagger}$ Srdan Begić,,${ }^{\ddagger}$ Fangfang Chen, ${ }^{\ddagger}$ Dmitrii Rakov, ${ }^{\ddagger}$ Driss Mazouzi, ${ }^{\|}$Nicolas

Gautier,${ }^{\dagger}$ Robert Kerr,${ }^{\ddagger}$ Bernard Lestriez,${ }^{\dagger}$ Jean Le Bideau, ${ }^{\dagger}$ Patrick C. Howlett,${ }^{\ddagger}$ Dominique

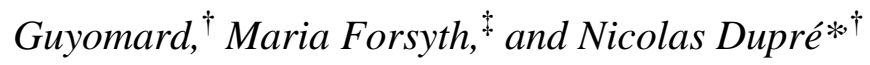

†Université de Nantes, CNRS, Institut des Matériaux Jean Rouxel (IMN), F - 44000, Nantes,

France

${ }^{\ddagger}$ Institute for Frontier Materials (IFM), Deakin University, 221 Burwood Highway, Burwood, Victoria 3125, Australia

${ }^{\S}$ French Environment and Energy Management Agency 20, avenue du Grésillé- BP 9040649004 Angers Cedex 01 France

$\|_{\text {Sidi Mohamed Ben Abdellah University, Materials, Natural Substances, Environment and }}$ Modeling Laboratory. Multidisciplinary Faculty of Taza. B.P.: 1223 Taza-Gare, Fes, Morocco 30000.

*corresponding author: nicolas.dupre@cnrs-imn.fr 
KEYWORDS: lithium-ion batteries, silicon, anode, solid electrolyte interphase, ionic liquid electrolytes, superconcentrated electrolytes

\begin{abstract}
The latest advances in the stabilization of Li/Na metal battery and Li-ion battery cycling has highlighted the importance of electrode/electrolyte interface (Solid Electrolyte Interphase - SEI) and its direct link to cycling behaviour. In order to understand the structure and properties of the SEI, we used combined experimental and computational studies to unveil how the ionic liquid (IL) cation nature and salt concentration impact the silicon/IL electrolyte interfacial structure and the formed SEI. The nature of IL cation is found to be important to control the electrolyte reductive decomposition that influences the SEI composition and properties, and the reversibility of the Li-Si alloying process. Also, increasing the Li salt concentration changes the interface structure for a favorable and less resistive SEI. The most promising interface for the Si-based battery was found to be in $\mathrm{P}_{1222} \mathrm{FSI}$ with $3.2 \mathrm{~m}$ LiFSI which leads to an optimal SEI after 100 cycles in which LiF and trapped LiFSI are the only distinguishable lithiated and fluorinated products detected. This study shows a clear link between the nano-structure of the IL electrolyte near the electrode surface, the resulting SEI, and the Si negative electrode cycling performance. More importantly, this work will aid rational design of Si-based Li-ion batteries using IL electrolytes in an area that has so far been neglected, reinforcing the benefits of superconcentrated electrolyte systems.
\end{abstract}

\title{
1. INTRODUCTION
}

Since the commercialization of lithium-ion batteries (LIBs) by Sony in 1991[1,2], graphite has dominated the market as the primary negative electrode material[3] due to its favorable physical and chemical characteristics. However, silicon $(\mathrm{Si})$ has gained considerable attention in the past 
decade or so and is generally considered now as the future negative electrode material for LIBs

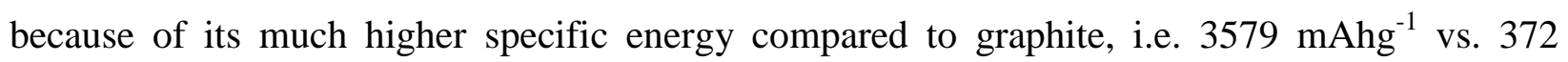
$\mathrm{mAhg}^{-1}$ [4-6]. However, one of the major drawbacks of using Si is its unstable solid electrolyte interphase (SEI) [6-8] that results from electrode pulverization upon repeated lithiation and delithiation. The silicon particles undergo up to $~ 300 \%$ volumetric changes [9] during cycling of the battery, causing the particles to crack and expose new surfaces where incessant breakdown of the electrolyte components takes place. Current systems are not so efficient in that this phenomenon is accompanied by the cracking of the SEI during the expansion of Si. Hence, the choice of other cell components is carefully considered in the design of Si-based batteries. For instance, binders are selected on the basis of having functional groups that can effectively graft with the hydroxyl groups on the native Si surface. Poly acrylic acid (PAA) [6] and carboxymethyl cellulose (CMC) [10] are well-known binders for silicon electrodes because they contain the necessary carboxyl groups. These binders were also found to be rigid which help in giving the electrode its mechanical integrity, while buffering the effects of silicon volume expansion. The use of electrolyte additives such as FEC [11,12] is also a well-known strategy to form a stable SEI in LIBs based on silicon negative electrode. The SEI resulting from an FECcontaining electrolyte commonly has LiF as a main component, which has been reported to have poor bulk ionic conductivity.[13] Thus, LiF may not always be beneficial; instead, it can be detrimental for the electrode if too much of it is incorporated in the SEI.

The SEI is an integral part in understanding the battery performance and failure as it plays a key role in the diffusion of $\mathrm{Li}$ ions to and from the electrode, and in preventing further breakdown of the electrolyte at the electrode surface. It is essentially a thin film with a complex structure formed by the reductive decomposition of the electrolyte on the negative electrode surface. Aside 
from using additives, alternative electrolyte compositions have been studied in an effort to enhance the SEI efficiency of Si-based negative electrodes and its dynamic nature. Over the past several years, there has been a growing interest in the use of ionic liquids (IL) in electrochemical devices [14] owing to their unique properties such as non-flammability, low volatility, high ionic conductivity, and good electrochemical and thermal stability.[15,16] Additionally, an improved control of the species making up the SEI can be achieved by employing ILs in Si-based batteries because of their inherent better chemical stability compared to the traditional carbonate-based electrolytes.[5,15]

While some IL electrolytes have already been used with $\mathrm{Si}$ negative electrodes [17,18], investigations relating to the SEI and interfacial chemistries are not as established as those in conventional electrolytes. Techniques such as MAS-NMR, SEM, TEM-EELS, and XPS are commonly used to examine the SEI composition and morphology.[19-21] However, in order to gain more essential information about its formation, it is important to understand the structural behaviour within the interfacial region, i.e. a few nanometers from the electrode surface, upon polarization. Several experimental methods such as AFM [22,23], neutron reflectrometry [24,25], vibrational [26,27] and impedance [28-30] spectroscopies, have all been successfully applied to thoroughly investigate the electrolyte nanostructuring and composition at an interface. In addition, the use of computational methods such as DFT and molecular dynamics [29,31-33] was found to be essential to further understand the changes in the potential-driven interfacial structure.

Our recent study [18] using superconcentrated electrolytes revealed the superior electrochemical behaviour of triethyl(methyl)phosphonium bis(fluorosulfonyl)imide $\left(\mathrm{P}_{1222}\right.$ FSI) in a half-cell investigation of Si negative electrodes (Fig. S1). This result was linked to the stability of the 
electrolyte upon cycling and to improved lithium ion transport which is facilitated at high Li salt content. In the present work, we report the importance of tuning the Si/IL electrolyte interface as a function of IL cation nature and salt concentration. Experimental techniques such as MASNMR, SEM, and STEM-EDX were used to determine the SEI composition and morphology in order to further investigate its influence on the electrochemical performance as well as the relationship of the electrolyte chemistry $\left(\mathrm{P}_{1222} \mathrm{FSI}\right.$ and $N$-methyl- $N$-propylpyrrolidinium $\left(\mathrm{C}_{3}\right.$ mpyr) FSI-based electrolytes) to the SEI properties. Differences with typical carbonate electrolytes are also highlighted. In addition, computational methods and differential capacitance (DC) experiments using AC impedance were applied to gain a better understanding of the SEI formation by examining the structuring at the electrode/electrolyte interphase.

\section{EXPERIMENTAL SECTION}

\subsection{Electrode Preparation}

Slurries were prepared from Si nanoparticles ( 150 nm diameter, S’tile) [34], sodium carboxymethyl cellulose $\left(\mathrm{Na}-\mathrm{CMC}, \mathrm{DS}=0.9, \mathrm{M}_{\mathrm{W}}=700,000\right.$, Sigma Aldrich) binder, graphene

nanoplatelets (GM15, length $\sim 15 \mu \mathrm{m}$, width $\sim 5-10 \mu \mathrm{m}, \mathrm{S}_{\mathrm{BET}}: 74 \mathrm{~m}^{2} \mathrm{~g}^{-1}$, XGSciences) conductive additive, polyacrylic co-maleic acid (Sigma Aldrich) dispersant in $\mathrm{pH} 3$ buffer solution with 71:7:11:2:9 wt.\% ratio.[6,35] A total of $200 \mathrm{mg}$ of the mix was transferred in a silicon nitride jar with three silicon nitride balls $(9.5 \mathrm{~mm}$ diameter $)$. One $\mathrm{ml}$ of de-ionized water was added as solvent. The slurries were mixed, tape cast on copper foil, and dried as described by Karkar et al..[6]

\subsection{Electrochemical Measurements}


$\mathrm{Li} \mid \mathrm{Si}$ Swagelok half-cells were assembled from Si electrode discs $\left(0.785 \mathrm{~cm}^{2}\right)$. A microporous polypropylene membrane (Celgard 3501) and a borosilicate glass-fiber (Whatman GF/A) were used as separators. IL electrolytes were prepared from $\mathrm{P}_{1222}$ FSI (Boron Molecular, Noble Park, VIC, Australia) and $\mathrm{C}_{3}$ mpyrFSI (Solvionic, France) containing LiFSI salt (Nippon Shokubai, Japan).[36] The purity of the ILs were confirmed with inductively coupled plasma mass spectroscopy (ICP-MS) while LiFSI was used directly as received. The electrolyte components were dried separately under vacuum for 48 hours at $50^{\circ} \mathrm{C}$ before mixing to get the desired salt concentration of 3.2 and $0.8 \mathrm{~m}$. The final water content of the IL electrolytes was $<20 \mathrm{ppm}$ (measured with an 831 Karl Fisher Coulometer). An organic carbonate electrolyte composed of LP 30 (1.0 M LiPF 6 in ethylene carbonate (EC):dimethyl carbonate (DMC) 50-50 by volume from Sigma Aldrich) with 10 wt.\% fluoroethylene carbonate (FEC) [37] was also prepared. The Si electrodes were pre-wetted with the electrolytes under vacuum for 18 hours at $50^{\circ} \mathrm{C}$. Six drops of the electrolytes were added after the pre-wetting step. The electrolyte preparation and cell assembly were performed in an Argon-filled glovebox. The cells were transferred to a $50^{\circ} \mathrm{C}$ oven after assembly to allow a rest period of 24 hours before the electrochemical measurements. The cycling experiments were performed using a VMP multichannel potentiostat (Bio-Logic). Using galvanostatic mode, cycling was performed at $50^{\circ} \mathrm{C}$ at $\mathrm{C} / 10$ rate (corresponding to $4 \mathrm{Si}+15 \mathrm{Li}$ in $\mathrm{n}$ hours) with voltage cutoffs at 1 and $0.01 \mathrm{~V}$.

\subsection{SEI Characterization}

Scanning electron microscopy (SEM) images were obtained using JEOL JSM 7600F microscope. The Si negative electrodes were prepared for surface and cross-sectional analysis by mounting the samples in SEM sample holders inside an Argon-filled glovebox. The samples were secured in an Ar-filled container for transfer to the SEM chamber. The transfer was 
performed as quick as possible to minimize sample exposure to ambient atmosphere. The exposure time is estimated to be less than 1 minute.

Transmission electron microscopy (TEM) imaging was performed using HNAR9000 microscope to obtain images of the pristine Si nanoparticles. The particles were dispersed in alcohol using an ultrasonic bath. The dispersion was placed in a copper grid (Lacey, 300 mesh) and transferred in the microscope for analysis. For the cycled Si electrodes, a Themis Z - STEM-EDX microscope was used to obtain images and elemental composition. The samples were prepared inside an Argon-filled glovebox by scraping off the Si electrode from the current collector and placing the copper grid (Lacey, 300 mesh) directly on the electrode material. The copper grids with the samples were then placed inside a transfer box and sealed prior to transfer to the microscope.

Magic Angle Spinning (MAS) - NMR (Bruker $500 \mathrm{MHz}$ Ultrashield spectrometer) was used to identify the composition of the Si electrodes after cycling in different electrolytes. The Si electrode was recovered after the end of delithiation and placed in a $2.5 \mathrm{~mm}$ zirconia rotor for ${ }^{7} \mathrm{Li}$ and ${ }^{19} \mathrm{~F}$ NMR analysis, using spinning frequencies of $25 \mathrm{kHz}$ and $23 \mathrm{kHz}$, respectively. Quantitative NMR was also performed by mixing $\mathrm{Si}$ with various amounts of $\mathrm{LiF}$ to obtain calibration curves which allow absolute quantification of the lithiated and fluorinated components in the samples.[38] Integrated intensities from the ${ }^{7} \mathrm{Li}$ and ${ }^{19} \mathrm{~F}$ NMR combined with these curves allow us to calculate the amount of $\mathrm{LiF}$ and other lithiated species. All the spectra were normalized to take into account the number of scans, the receiver gain, and the mass of the sample. The spinning sidebands were also taken into account.[5,39] Fitting of all the spectra was performed using the dmfit program.[40]

\subsection{Measurements by AC Impedance}


EIS measurements were conducted at $55^{\circ} \mathrm{C}$ using a 3-electrode setup inside an Ar-filled glovebox. The working electrode used is a semiconductive glassy carbon (GC). The counter electrode is a platinum $(\mathrm{Pt})$ wire and the reference electrode is silver triflate (AgOTf) filled with the tested ILs $(\sim 0.01 \mathrm{M})$. The electrodes were polished twice before each new measurement using a microdisc cloth covered with alumina ( 0.3 microns) for approximately 2 minutes each. After each polishing, the electrodes were rinsed with distilled (DI) water and sonicated for 5 minutes. The electrodes were rinsed again with DI water and ethanol then dried with Ar flow and later in a $70^{\circ} \mathrm{C}$ oven. The electrode cleaning and the 3 -electrode setup were performed based on the method of Klein et al.[41] The EIS frequency range was set between $400 \mathrm{kHz}$ to $1 \mathrm{~Hz}$ with an amplitude of $10 \mathrm{mV}$ and the impedance was recorded at different applied potentials, between 0.7 $\mathrm{V}$ to $-1.85 \mathrm{~V}$ vs. $\mathrm{Ag} / \mathrm{Ag}^{+}$. Prior to this, $\mathrm{CV}$ measurements were carried out between $0.9 \mathrm{~V}$ to -1.9 $\mathrm{V}$ vs. $\mathrm{Ag} / \mathrm{Ag}^{+}$to verify that the EIS experiments are within the stability window of the electrolytes. The absolute potential scale was converted to $\mathrm{Fc} / \mathrm{Fc}^{+}$by calibrating the reference electrode in the tested IL with traces of ferrocene. The differential capacitance of the different electrolyte systems was then calculated by fitting the EIS data to the appropriate equivalent circuit model. The model used (Fig. S2) consists of the electrolyte resistance in series with a constant phase element, that is in parallel to a resistor, which describes the deviation from a nonideal capacitive behaviour. The electrical double layer (EDL) capacitance was calculated by first identifying the frequency close to the 90-degree phase angle of the Bode plot which corresponds to capacitive behaviour. The capacitance was then explicitly calculated using the equation mentioned in the literature.[41]

\section{RESULTS AND DISCUSSION}

\subsection{Interfacial Morphology and Topography using SEM and STEM-EELS}


Electrochemical performance of Si electrode in the IL electrolytes and traditional carbonatebased electrolytes at $50^{\circ} \mathrm{C}$ at $\mathrm{C} / 10$ are provided in Figure $\mathrm{S} 1$. SEM observation of the $\mathrm{Si}$ electrodes recovered after 100 cycles at the end of delithiation reveals key differences between the electrodes cycled in the carbonate and IL electrolytes, but significant similarities between those cycled in superconcentrated pyrrolidinium and phosphonium IL systems. Surface analysis shows that cycling in conventional carbonate electrolyte, i.e. LP30 $+10 \mathrm{wt} \% \mathrm{FEC}$, results in deep cracks that span the entire surface of the electrode (Fig. 1a) compared to the pristine $\mathrm{Si}$ electrode (Fig. S3 a-b). This is an indication of a mechanically weak electrode and SEI that break down as $\mathrm{Si}$ undergoes severe volume expansion and contraction during lithiation and delithiation, respectively. The ideal particle size of Si for practical use as anodes in LIBs is below $150 \mathrm{~nm}$ [42], which anticipates huge volumetric changes with the Si used in this work as the particles have an average diameter of about $150 \mathrm{~nm}$ (Fig. S4 a-b). The presence of such deep cracks most probably electrically isolates parts of the Si active material and could be one of the key contributors of the drastic capacity decay as previously observed [18] (Fig. S1). In contrast, the absence of prominent cracks across the surface of the electrodes even after long-term cycling in the IL electrolytes (Figs. 1c and 1e) could indicate a more robust or flexible SEI. Domi et al.[43] and Yodoya et al.[44] also reported the ability of IL electrolytes to suppress the formation of cracks in silicide-based electrodes and the disintegration of P-doped Si electrodes, respectively. As shown here, the SEI appears to have formed a compact film, and possibly filled the cracks in the $\mathrm{Si}$ particles which can form during cycling; this seems to maintain the $\mathrm{Si}$ particles intact and prevent significant crack formation. This IL-based SEI may somehow act as a binder which keeps the integrity of the electrode during battery cycling by 'gluing' the $\mathrm{Si}$ particles together, even after pulverization. 
In addition to surface morphology, cross-sectional examinations were performed to determine the expansion of the $\mathrm{Si}$ anodes after extended operation. It seems that cycling in carbonates results in a thinner overall electrode relative to the behaviour with the IL electrolytes as shown in Figs. $1 \mathrm{~b}, 1 \mathrm{~d}$, and 1f. The resulting electrode thickness is $54 \mu \mathrm{m}, 66 \mu \mathrm{m}$, and $68 \mu \mathrm{m}$ after 100 cycles in LP $30+10 \mathrm{wt} \%$ FEC, $\mathrm{C}_{3}$ mpyrFSI-LiFSI, and $\mathrm{P}_{1222}$ FSI-LiFSI, respectively, compared to an average of $22 \mu \mathrm{m}$ (Fig. S3 c) for a pristine Si electrode. This result is in contrast with an earlier study [45] where carbonate electrolytes produced the thickest electrodes. However, in this work, the thinner electrode post cycling in carbonate is attributed to its shorter operating period of about 60 cycles, i.e. capacity fades drastically [18] due to the possible electrical isolation of the Si particles accompanied by electrolyte decomposition at $50^{\circ} \mathrm{C}$. On the other hand, the cells with IL electrolytes could cycle for longer time at full capacity [18], resulting in a more significant volume variation, even compared to our previous report [37]; hence, the larger electrode expansions. The similar electrode thickness in the two IL systems suggests that their different electrochemical behaviour is not primarily a consequence of their SEI morphological characteristics but may be due to a difference in their SEI composition/properties and/or SEI component distribution. Nevertheless, the formed IL-based SEI appears to provide more resilience against volume variation compared to the case of Si electrodes cycled in carbonates: after 100 cycles, electrodes cycled with IL based electrolytes achieved a larger swelling due to the SEI formation, as can be inferred from the thickness (Fig.1d and f) of the electrode, while maintaining a complete integrity with insignificant degree of cracking, as opposed to the case of the carbonate electrolyte. 

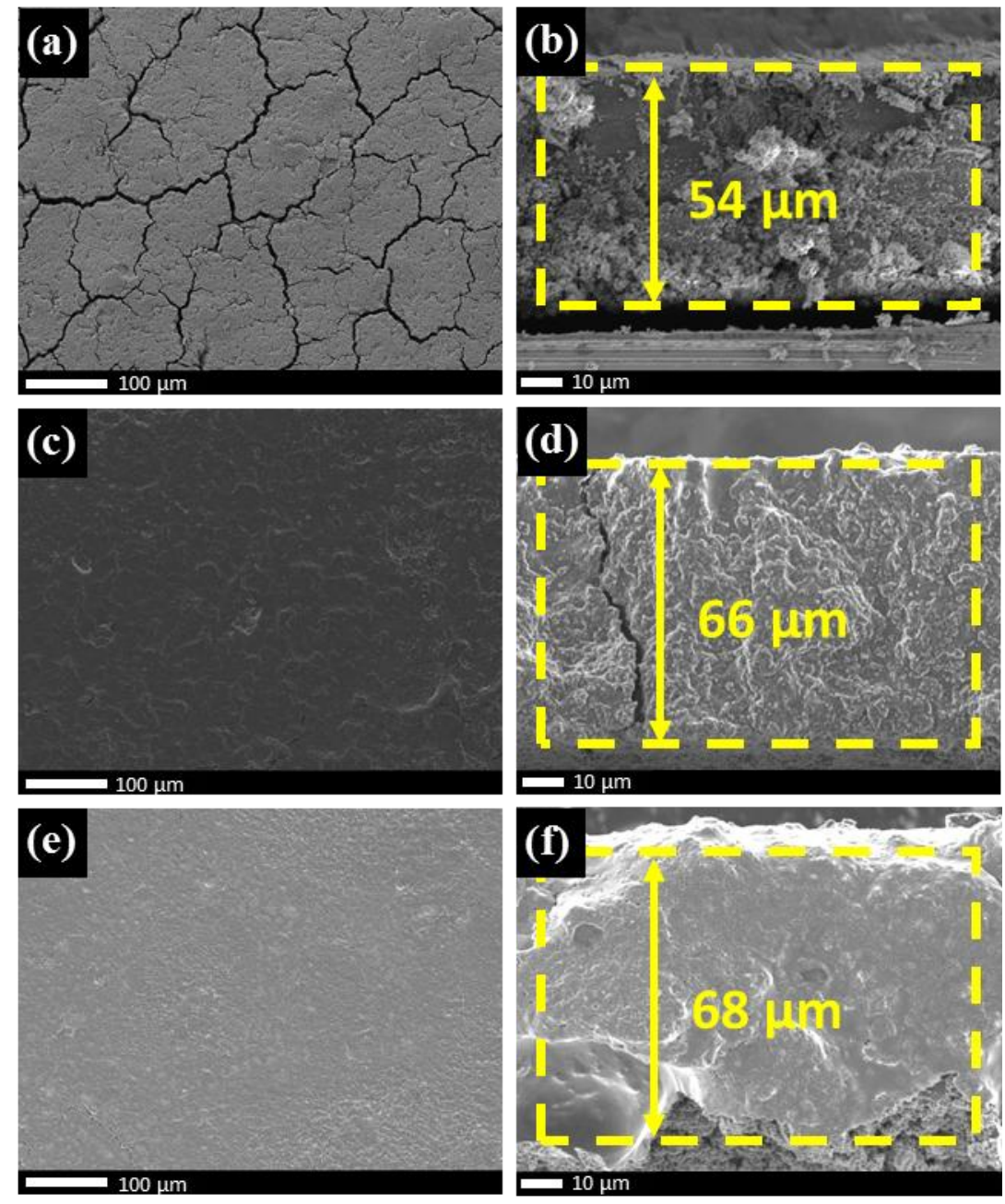

Figure 1. Surface and cross-sectional SEM micrographs of the Si electrodes after $100^{\text {th }}$ delithiations in (a-b) LP $30+10 \mathrm{wt} \%$ FEC (c-d) $3.2 \mathrm{~m} \mathrm{LiFSI}$ in $\mathrm{C}_{3}$ mpyrFSI, and (e-f) $3.2 \mathrm{~m}$

\section{LiFSI in $\mathrm{P}_{1222} \mathrm{FSI}$}

High resolution STEM-EDX mapping were used to gain insight into the topography of the electrodes and their elemental constituents and distribution. Figs. 2a-2c confirm the breakdown of the Si particles after long-term cycling. They no longer appear as $150 \mu \mathrm{m}$ round particles but rather as long filaments formed by smaller particles, as highlighted in red in Fig. 2d. In addition, silicon filaments are completely covered by a glue-like SEI that binds the Si particles together. All the probed elements that are possibly involved in the SEI formation, i.e. F, O, N, S, and P 
(for the phosphonium system), are found in all the corresponding examined areas (Fig. S5), confirming that this glue-like coating constitutes the SEI. Using EDX, we reveal that FSI anion degradation products clearly take part in the SEI composition since the N:S:F = 1:2:2 ratio expected for the non-degraded FSI anion, is not found (Table S1 and S2). Breaking of the S-N-S bond within FSI fragments is also evident since the 1:2 (N:S) ratio is also not satisfied. Furthermore, the O:S ratio indicates breaking of the $\mathrm{S}=\mathrm{O}$ anion backbone. It is not uncommon to observe the breakdown of FSI anions which typically yield LiF.[46,47] MAS NMR analysis, as discussed in detail later on, reveals the dominating presence of LiF. Additionally, other decomposition species such as $\mathrm{Li}_{2} \mathrm{~S}, \mathrm{Li}_{2} \mathrm{NSO}_{2} \mathrm{~F}, \mathrm{LiSO}_{2}, \mathrm{Li}_{2} \mathrm{O}$, and possibly $\mathrm{Li}_{2} \mathrm{CO}_{3}$ may result from the breakdown of the FSI anion.[21]

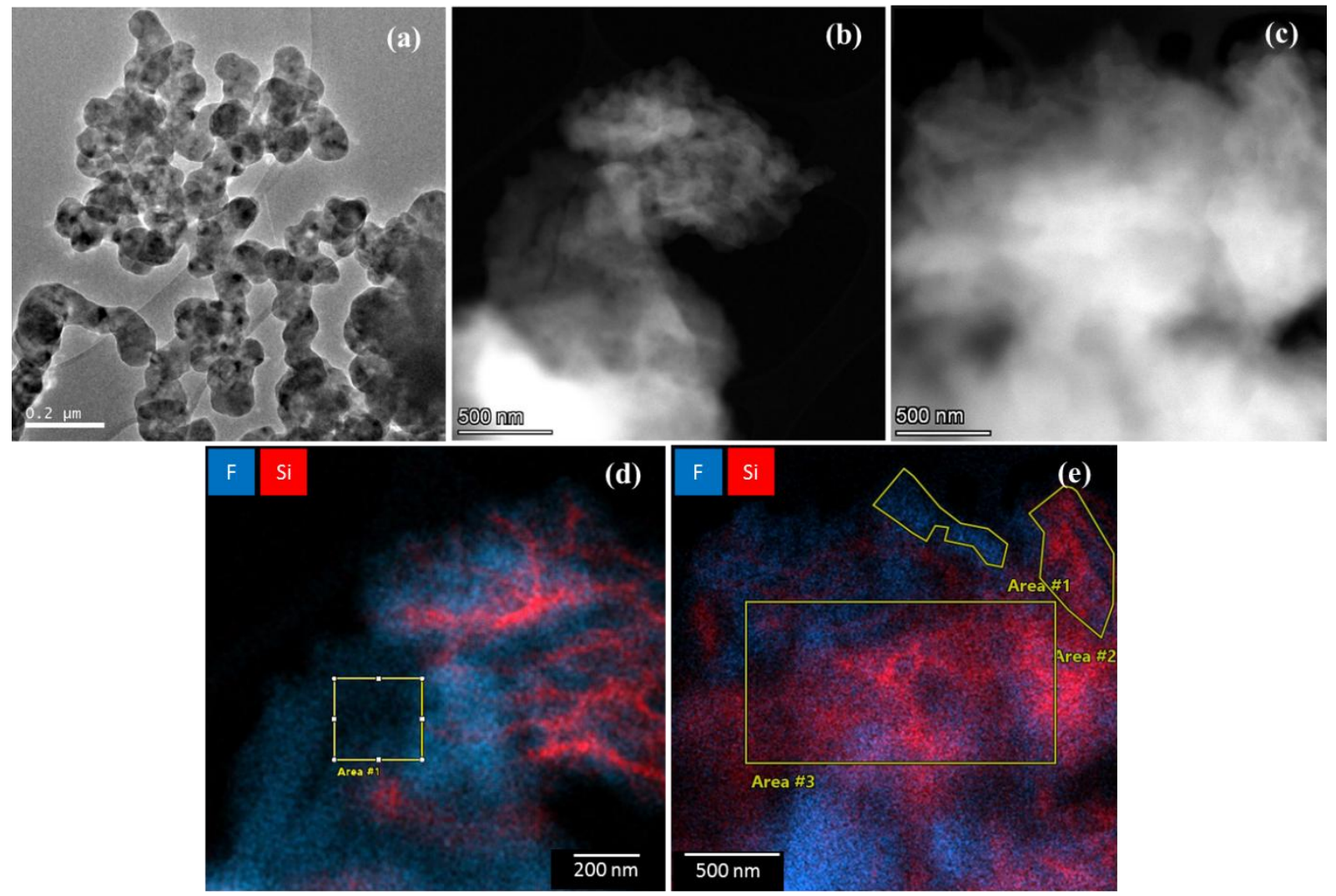

Figure 2. STEM-EDX images of the (a) pristine Si nanoparticles, and the Si electrode after $100^{\text {th }}$ delithiation in (b and d) $\mathrm{P}_{1222} \mathrm{FSI}$ with $3.2 \mathrm{~m} \mathrm{LiFSI}$ and (c and e) $\mathrm{C}_{3}$ mpyrFSI with $3.2 \mathrm{~m} \mathrm{LiFSI}$. 
(areas delimited in yellow correspond to the regions analyzed for elemental quantification in

\section{Table S1 and S2)}

STEM-EDX is also an excellent tool to observe any inhomogeneities in the SEI composition or distribution. Careful examination of the images reveals some notable features of the Si negative electrodes after 100 cycles in the IL electrolytes (Fig. $2 \mathrm{~d}$ and 2e). The two systems appear to have certain areas that are Si-rich and areas that are Si-poor, a characteristic that is more pronounced in the phosphonium system. The Si-poor regions seem to correspond to regions particularly rich in $\mathrm{F}$ and are reasonably assigned to LiF and FSI decomposition products. The composition distribution is rather inhomogeneous because some areas are very rich in fluorine ( 20-60\% at.) suggesting that they correspond to $\mathrm{LiF}$ rich areas, while other regions are characterized by a lower amount of fluorine ( $\sim 6-20 \%$ at.) suggesting the presence of more mixed $\mathrm{LiF}$ and FSI decomposition products or non-degraded LiFSI that could be trapped in the formed SEI. Nevertheless, the segregated distribution of $\mathrm{Si}$ and the SEI products in the phosphonium electrolyte based on the visual examination from STEM-EDX could present better accessibility of $\mathrm{Si}$ active sites for lithiation, favouring better charge transfer. Previously, we have shown through cell impedance data that extended cycling in pyrrolidinium presents a more blocking interphase.[18] In Fig. 2e, the more extensive covering of the SEI layer around silicon particles cycled in $\mathrm{C}_{3}$ mpyrFSI-LiFSI provides a strong indication that the pyrrolidinium system more readily undergoes decomposition to form a film around the active material. In addition to $\mathrm{LiF}$, the SEI layer is also composed of organic $\mathrm{C}_{3} \mathrm{mpyr}^{+}$breakdown products [18] which are poorly conducting to Li ions [48]. STEM-EDX mapping (Fig. S5) also indicates the presence of nitrogen and phosphorus, indicating that pyrrolidinium and phosphonium cations or their breakdown products are present in the SEI. Evidence of pyrrolidinium and phosphonium IL 
nanostructuring at the electrode surface and its consequence on their decomposition pathway is described in the computational section and using differential capacitance analysis discussed below.

\subsection{MAS NMR}

\subsubsection{Qualitative MAS NMR}

MAS NMR has been used by several studies [5,19,21,49] to investigate the chemical composition of the SEI in batteries. Here, we used ex situ MAS NMR to probe the bulk electrode and acquire global information about the nature of the SEI layer formed by the interaction of the Si with the various electrolytes. Previous NMR studies $[4,49,50]$ by our group using carbonate electrolytes reported that all $\mathrm{Li}$ is extracted from $\mathrm{Si}$ at the end of charge. Thus, experiments were performed at the end of the delithiation process of the $\mathrm{Si}$ in order to detect only $\mathrm{Li}$ nuclei involved in the SEI. The normalized integrated intensity of ${ }^{7} \mathrm{Li}$ NMR spectra of the electrodes cycled in the $\mathrm{C}_{3}$ mpyrFSI system in Fig. 3a show one broad resonance centered at $-2.0 \mathrm{ppm}$. Dupré et al.[5] pointed out resonances of $\mathrm{Li}_{\mathrm{x}} \mathrm{Si}$ alloys centered at $1.6 \mathrm{ppm}$, assigned to lithium rich areas including isolated silicon nuclei, in the case of nano-structured silicon. Other reports indicate the more common presence of Li-poor and Li-rich alloys at about $18 \mathrm{ppm}$ and $6 \mathrm{ppm}$, respectively.[50,51] The broad signal displayed in Fig. 3a thus confirms, in the case of IL electrolytes, the presence of Li only in the SEI and not Li trapped as $\mathrm{Li}_{\mathrm{x}} \mathrm{Si}$ in the $\mathrm{Si}[49,51]$ at the end of charge. The signal shift to negative values strongly suggests the presence of lithiated fluorinated species [5] and is consistent with LiF and LiFSI, indicating their contributions to the

broad peak at $-2.0 \mathrm{ppm} .{ }^{19} \mathrm{~F}$ NMR confirms unambiguously the presence of LiF as discussed in more detail below. LiF is known to be the most typical reduction product of the FSI salt anions $[18,47]$ and a dominant SEI component $[5,19]$ in most electrolyte formulations. The broad peak 
from ${ }^{7} \mathrm{Li}$ spectra may also overlap with signals from other lithiated compounds including $\mathrm{Li}_{4} \mathrm{SiO}_{4}$ (-1 to 2.5 ppm [49]), $\mathrm{LiOH}$ (0.4 ppm for $\mathrm{LiOH} . \mathrm{H}_{2} \mathrm{O}$ [52]), $\mathrm{Li}_{2} \mathrm{~S}$ (2.3 ppm [53]), and $\mathrm{Li}_{2} \mathrm{SO}_{4}(0$ ppm [54]) among others. Some of these products are a result of FSI anion decomposition, which supports our findings from STEM-EDX and is also in good agreement with our previously reported XPS results.[18] S 2p and O 1s XPS revealed the presence of $\mathrm{LiOH}, \mathrm{Li}_{2} \mathrm{~S}$, and $-\mathrm{SO}_{2} \mathrm{~F}$ groups after 100 cycles in the same conditions as the electrodes investigated in this work. Also, the presence of such products prior to electrochemical cycling is expected $[5,47]$ and suggests the spontaneous reaction of the electrolyte components with the Si. As illustrated in Fig. 3a, the SEI film then continues to grow and become more pronounced upon cycling.

From ${ }^{19}$ F NMR, the strong, characteristic [5,21] resonance at -205 ppm (Fig. 3b) verifies the presence of LiF. Additionally, a closer inspection reveals the presence of other decomposition products prior to cycling as seen in Fig. 1c. The signals at $-78 \mathrm{ppm}$ and $-140 \mathrm{ppm}$ are assigned to an $-\mathrm{SO}_{2} \mathrm{~F}$ group, e.g. $\mathrm{LiSO}_{2} \mathrm{~F}$, and $\mathrm{SiO}_{\mathrm{y}} \mathrm{F}_{\mathrm{x}}$, respectively.[18,55] These species are no longer visible in the spectra after several to a hundred cycles, consistent with previous reports $[21,56]$ where $\mathrm{LiSO}_{2} \mathrm{~F}$ was found to disappear upon cycling as more $\mathrm{LiF}$ is formed. However, such species may still exist but appear undetectable in the NMR after several cycles because of their overlapping signals with the intense peak and sidebands of LiF. As can be seen after 10 or 100 cycles, the ${ }^{19} \mathrm{~F}$ resonance obtained and assigned to $\mathrm{LiF}$ is not symmetric and a shoulder appears at $-199 \mathrm{ppm}$ in addition to the expected $-205 \mathrm{ppm}$ position for LiF. This suggests at least two different fluorine local environments. Nevertheless, the ${ }^{19} \mathrm{~F}$ chemical shift for LiF is quite specific and there is no other possible fluorinated compound that would lead to the rise of a resonance this close to that of $\mathrm{LiF}$. The shifted component of this asymmetric resonance is then tentatively assigned to a LiF-like environment, including an additional contribution to a purely 
chemical shift. NMR studies [57,58] of ion adsorption on microporous carbonaceous materials indicated that regardless of the nucleus $\left({ }^{2} \mathrm{H},{ }^{7} \mathrm{Li},{ }^{31} \mathrm{P},{ }^{19} \mathrm{~F}\right)$ or its charge (cation, anion), a -8 to -12 ppm shift is observed with respect to the expected position (e.g. when there is no interaction with a nearby aromatic ring). Moreover, negative shifts of diamagnetic Li have been reported in the case of Li cation surrounded by the $\pi$ electron clouds generated by graphite [59]. This behaviour has also been observed in ${ }^{7} \mathrm{Li}$ and ${ }^{19} \mathrm{~F}$ NMR in the case of LiF forming on the surface of graphite [60]. Such a negative shift corresponds to a physical adsorption and occurs when no chemical bond is formed. Here, a change towards a more positive chemical shift indicates instead that the electronic density on the p orbitals of $\mathrm{F}$ is increased, suggesting that there is a chemical reaction between $\mathrm{LiF}$ and the surface of the electrode leading to the observed LiF-like fluorine local environments. Qualitatively, similar results are obtained in the phosphonium system and are presented in Fig. S6. Apart from the resonance assigned to LiF at -205 ppm, the only remaining signal observed after 10 or 100 cycles appears at 52 ppm and corresponds to non-degraded FSI groups, including most probably LiFSI trapped in the SEI and in the electrode pores. On all spectra, this FSI signal contains one extremely sharp and one broader component (Fig. S7) that can be attributed to mobile, liquid-like non degraded $\mathrm{FSI}^{-}$anions and non- or less-mobile confined FSI containing species, such as LiFSI. Ferdousi et al.[61] recently reported the formation of complexes suggested to be $\mathrm{Na}_{2}\left[\mathrm{SO}_{3}-\mathrm{N}-\mathrm{SO}_{2} \mathrm{~F}\right] \cdot \mathrm{nH}_{2} \mathrm{O}(\mathrm{n}=0-2)$ in $\mathrm{Na}$ system, resulting from partial decomposition of FSI. In these complexes, the local environment of fluorine is expected to be close to that in FSI anion and the corresponding ${ }^{19} \mathrm{~F}$ NMR shift close to that of the non-degraded FSI signal. It is therefore possible that the broad resonance at $52 \mathrm{ppm}$ assigned to non-degraded FSI contains also a contribution from such complexes. No other fluorinated species were detected. Therefore, the above NMR results point out that the fluorine- 
rich areas analyzed by STEM-EDX most probably contain a mix of LiF, trapped LiFSI, a possible contribution from FSI-like complexes and other non-fluorinated degradation products such as $\mathrm{Li}_{2} \mathrm{~S}, \mathrm{LiSO}_{2}, \mathrm{Li}_{2} \mathrm{O}$, and possibly $\mathrm{Li}_{2} \mathrm{CO}_{3}$ that may result from the complete breakdown of the FSI anion.[21]
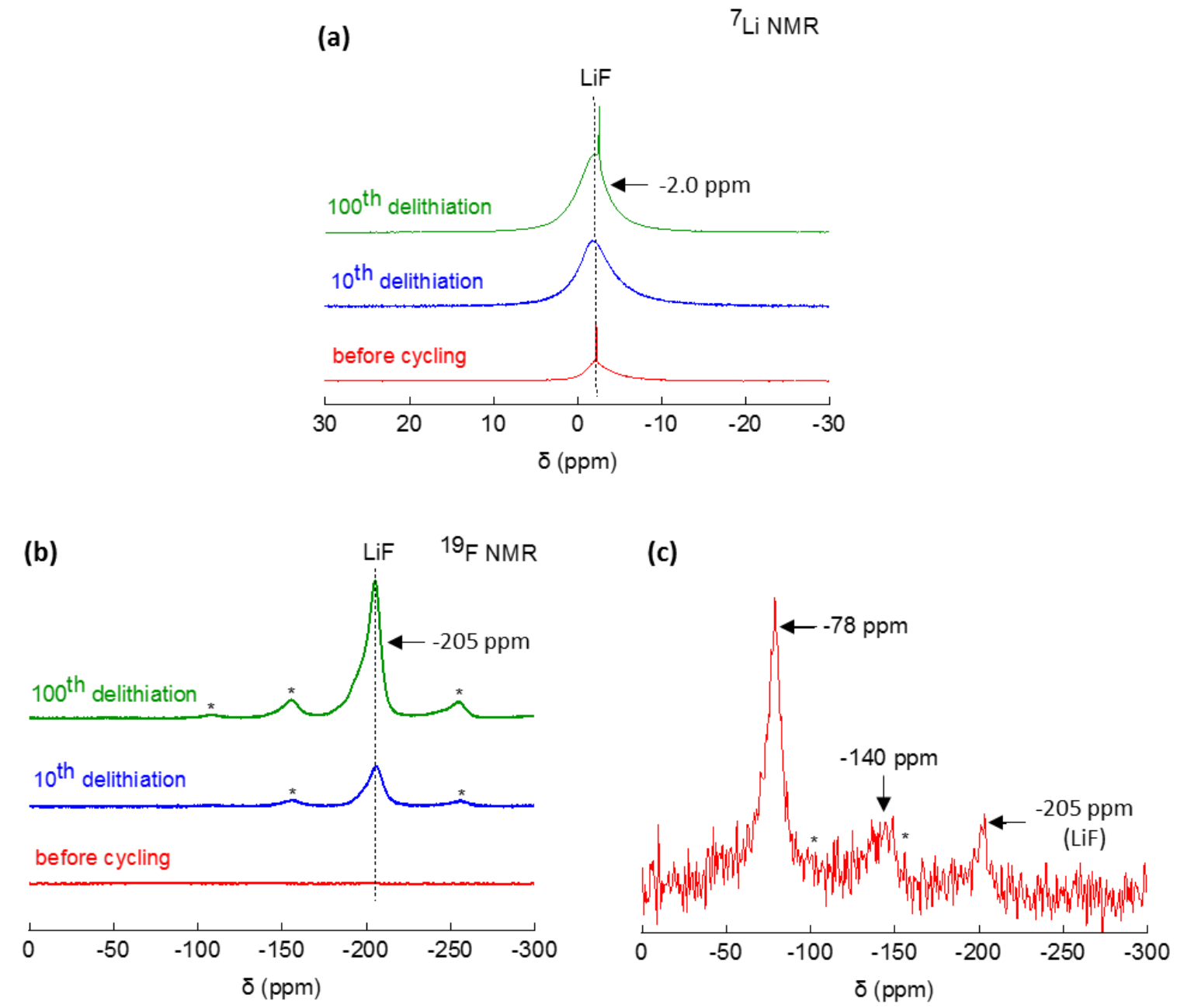

Figure 3. Normalized a) ${ }^{7}$ Li MAS NMR b) ${ }^{19}$ F MAS NMR spectra of the Si electrodes before and after cycling and c) Zoomed-in ${ }^{19}$ F MAS NMR spectra of Si electrodes before cycling in $\mathrm{C}_{3}$ mpyrFSI with $3.2 \mathrm{~m} \mathrm{LiFSI} \mathrm{(*} \mathrm{represents} \mathrm{spinning} \mathrm{sidebands)}$ 


\subsubsection{Quantitative MAS NMR}

Using the same spectra presented in Fig. 3, we report here an absolute quantification of LiF and other lithiated species with the aid of calibration curves (Fig. S8). This method was previously developed by our team [38] and has been successfully applied to investigate the SEI of battery electrodes. Please note that ${ }^{7} \mathrm{Li}$ quantification encompasses all products under the broad ${ }^{7} \mathrm{Li}$ resonance (e.g. $\mathrm{LiF}, \mathrm{LiFSI}, \mathrm{LiOH}, \mathrm{Li}_{2} \mathrm{~S}, \mathrm{Li}_{4} \mathrm{SiO}_{4}$ ) and it is not possible to quantify their respective contributions. On the other hand, LiF quantification from ${ }^{19} \mathrm{~F}$ MAS NMR is easier, thanks to the very specific chemical shift of LiF. In addition, due to the usually long relaxation time of NMR signals from liquid-like species, the resonance corresponding to mobile liquid-like FSI observed here is probably not quantitative (and was in most cases truncated) and therefore cannot be used for quantification of remaining FSI species in the studied samples. On the contrary, ${ }^{7} \mathrm{Li}$ signal is obtained in quantitative conditions, ensuring the detection of possible LiFSI amongst other lithiated species. The values in $\mu \mathrm{mol} / \mathrm{mg}_{\text {active material }}$ are summarized in Fig. 4. For each sample, quantitative amounts of $\mathrm{LiF}$, first obtained from ${ }^{19} \mathrm{~F}$ MAS NMR, were subtracted from the total amount of lithium detected with ${ }^{7} \mathrm{Li}$ MAS NMR. This allows monitoring the evolution of the so-called "other lithiated species".

\section{a) Influence of the electrolyte nature at high LiFSI concentration}

Focusing first on the concentrated system, during the early stages of cycling, the electrodes cycled in $\mathrm{P}_{1222}$ FSI-LiFSI yields more LiF (Fig. 4a) compared to the electrodes cycled in the $\mathrm{C}_{3}$ mpyrFSI-LiFSI electrolyte. It should be noted that the species probed with ${ }^{7} \mathrm{Li}$ and ${ }^{19} \mathrm{~F}$ MAS NMR in this case are products of LiFSI decomposition. Hence, we attribute these results to the more extensive breakdown of the FSI anion in the case of the phosphonium systems. With 
regard to pyrrolidinium, $\mathrm{C}_{3} \mathrm{mpyr}^{+}$undergoes breakdown early on cycling [18], which may compete with and delay the FSI decomposition. This is explored in the subsequent MD section.

The most striking results from ${ }^{7} \mathrm{Li}$ and ${ }^{19} \mathrm{~F}$ MAS NMR quantification is observed after extended cycling (Fig 4b and 4d). While we recognize the probable presence of other products that are not lithiated and/or fluorinated, and therefore not detectable using ${ }^{7} \mathrm{Li}$ and ${ }^{19} \mathrm{~F}$ MAS NMR, including IL cations or their decomposition products, we found that the fundamental difference between the SEI nature after cycling in the superconcentrated electrolytes is that all the lithium is present only as LiF in the case of pyrrolidinium system. On the contrary, in the case of the phosphonium system, a mixture of lithiated species, i.e. LiF and other lithiated species including trapped LiFSI, as detected by ${ }^{19} \mathrm{~F}$ MAS NMR, are formed after 100 cycles. Moreover, the amount of lithium nuclei involved in LiF is of the same order of magnitude as those comprised of other lithiated species (Fig. 4b), indicating a significantly mixed composition of the SEI in terms of lithiated species. Although LiF consistently appears as a main SEI component, its role in Sibased LIBs remains unclear to this date. Some issues have been raised despite its ability to provide a stable protective layer to the Si electrode owing to its high bonding energy [62], which could also have contributed to its signal shifting to $-199 \mathrm{ppm}$ in ${ }^{19} \mathrm{~F}$ NMR, as mentioned earlier. The electronically insulating nature of $\mathrm{LiF}$ may cause the active Si particles to lose electrical contact and lead to capacity loss [63]. Additionally, an LiF-rich interphase may result in poor charge transfer because of its low bulk ionic conductivity [13]. It is also reported that the diffusion of $\mathrm{Li}^{+}$in $\mathrm{LiF}$ is low compared to other compounds such as $\mathrm{LiOH}$ and $\mathrm{Li}_{2} \mathrm{O}$ that are commonly found in the SEI.[64,65] Between pyrrolidinium and phosphonium systems at high LiFSI concentration, we have shown previously [18] that the EIS Nyquist plot obtained after 100 cycles for the former exhibits an additional, clearly defined second semi-circle, compared to the 
latter, indicating a significant additional resistive contribution (Fig. S9a and b). This confirms the higher interfacial resistance (Table S3), after 100 cycles in the case of the superconcentrated pyrrolidinium-based electrolyte. On the basis of these findings, it is expected that it is beneficial to have a good balance of $\mathrm{LiF}$ and other lithiated species in the SEI. This result is also in agreement with the better electrochemical performance and more stable cyclability obtained in the case of the phosphonium system (Fig. S1).

\section{b) Influence of the LiFSI concentration}

A comparative investigation of the influence of salt concentration confirms the large contribution of $\mathrm{LiF}$ to the chemical composition of the SEI. After 10 cycles, a trend similar to what has been observed for the concentrated system is noticed with more LiF (Fig. 4c) produced in the case of electrodes cycled in $\mathrm{P}_{1222} \mathrm{FSI}-\mathrm{LiFSI}$ compared to the electrodes cycled in the $\mathrm{C}_{3} \mathrm{mpyrFSI-LiFSI}$ electrolyte, although the difference is lessened for the low concentrated systems. Another interesting feature is that in the case of the pyrrolidinium system, at low LiFSI concentration, the amount of lithium involved in species other than $\mathrm{LiF}$ is twice that of the $\mathrm{LiF}$ component. This will be discussed below, in relation to MD results.

After 100 cycles, it is observed in both phosphonium and pyrrolidinium electrolytes that more $\mathrm{LiF}$ is generated with the addition of $3.2 \mathrm{~m} \mathrm{LiFSI}$ salt compared to $0.8 \mathrm{~m} \mathrm{LiFSI}$. Also, the ratio between $\mathrm{Li}$ ions involved in other lithiated species and $\mathrm{Li}$ ions involved in $\mathrm{LiF}$ is significantly higher than 1 (1.3 and 1.9 at $0.8 \mathrm{~m} \mathrm{LiFSI}$ for the phosphonium and pyrrolidinium system, respectively), showing a stronger contribution of lithiated species other than the resistive $\mathrm{LiF}$ to the SEI. This translates to a lower cell impedance for low salt concentration (Fig. S9 a-b), indicating the formation of a non-blocking SEI. Overall, the common species in the interfacial constituents, i.e. mixture of a slight minority of LiF, a majority of other lithiated species, and IL 
cation degradation products [18], after cycling in the two dilute IL electrolytes could explain their similar behaviour. Therefore, the poor electrochemical performance obtained after an extended cycling in the low concentration system seems to be due to the degradation of the electrolyte rather than the formation of a blocking and resistive SEI.[18] The phenomenon leading to these observations can be described by the electrolyte nanostructuring at the electrode/electrolyte interface upon polarization, as discussed in the succeeding sections. In the case of superconcentrated systems, the ratio of Li ions involved in other lithiated species with respect to those involved in $\mathrm{LiF}$ formation is close to 1 for the phosphonium system, whereas all the lithium is in LiF for pyrrolidinium. Nyquist plots (Fig. S9a-b) confirms that both scenarios lead to a higher impedance compared to the dilute electrolytes. The estimated interfacial resistance is summarized in Table $\mathrm{S} 3$. 

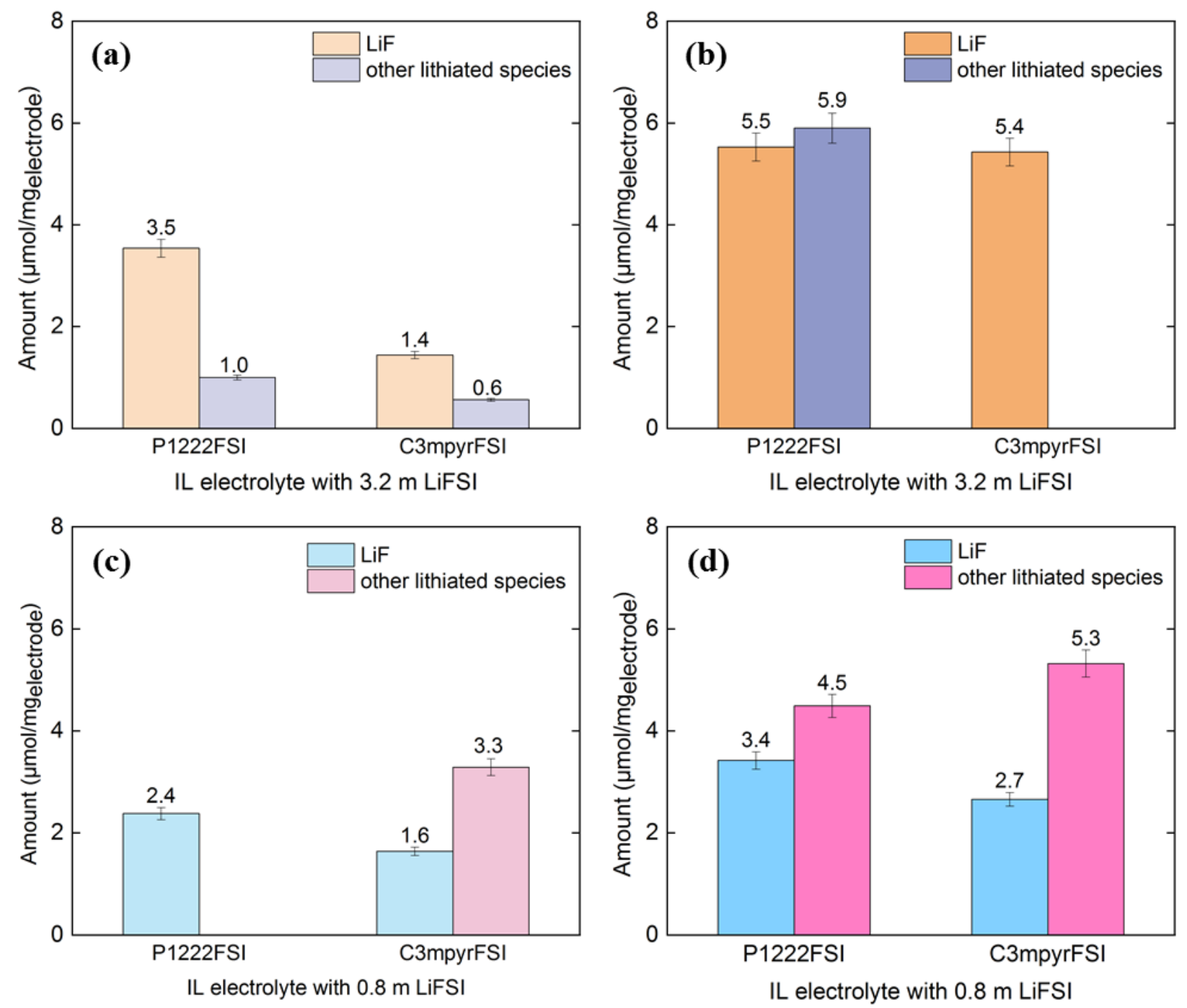

Figure 4. Amount of $\mathrm{LiF}$ and other lithiated components on the Si electrodes derived from ${ }^{19} \mathrm{~F}$ NMR and ${ }^{7}$ Li NMR after a) $10^{\text {th }}$ delithiation and b) $100^{\text {th }}$ delithiation in $C_{3}$ mpyrFSI-LiFSI and $\mathrm{P}_{1222}$ FSI-LiFSI with $3.2 \mathrm{~m} \mathrm{LiFSI}$ and c-d) the same conditions with $0.8 \mathrm{~m} \mathrm{LiFSI}$

As opposed to ILs, ${ }^{7} \mathrm{Li},{ }^{19} \mathrm{~F}$, and ${ }^{31} \mathrm{P}$ MAS NMR experiments performed on the electrodes cycled in LP $30+10 \mathrm{wt} \%$ FEC confirm the unfavorable interaction of a standard battery electrolyte with Si. The strong resonance centered at $-1.6 \mathrm{ppm}$ and $-205 \mathrm{ppm}$ in ${ }^{7} \mathrm{Li}$ and ${ }^{19} \mathrm{~F}$ spectra (Fig. S10 a-b), respectively, indicate the presence of $\operatorname{LiF}[5,21]$. Calculations (Table 1) reveal a total of $10.3 \mu \mathrm{mol} / \mathrm{mg}_{\text {electrode }}$ of $\mathrm{LiF}$ after 100 cycles, which is twice the amount found in the IL-cycled 
electrodes. In fact, almost identical amounts of $\mathrm{LiF}$ are found after the $10^{\text {th }}$ and $100^{\text {th }}$ delithiation in the carbonate and IL electrolytes, respectively. This means that as early as 10 cycles, the formation of decomposition products has started to negatively impact the performance of Si in the carbonate electrolyte. The capacity fades continuously until there is almost negligible capacity after about 60 cycles. In addition, there is smaller contribution, appearing as a shoulder at about $0.5 \mathrm{ppm}$ in Fig. S6 which is attributed lithium organic species amounting to 1.6 $\mu \mathrm{mol} / \mathrm{mg}_{\text {electrode }}$ after 10 cycles.

Table 1. Amount of $\mathrm{LiF}$ and other lithiated species on the $\mathrm{Si}$ electrodes after $10^{\text {th }}$ and $100^{\text {th }}$ delithiation in the IL-based electrolytes and carbonate-based electrolyte. *: assumed to be less than $5 \%$, considering the uncertainties on the estimation of the total amounts of lithium and the total amount of lithium implicated in LiF. In addition, in the case of the ${ }^{7} \mathrm{Li}$ MAS NMR spectrum of the electrode cycled in carbonate electrolyte after 100 cycles, contributions that could be assigned to lithiated organic species and to $\mathrm{LiF}$ exhibit a strong overlapping resonance preventing a reliable deconvolution.

\begin{tabular}{|c|c|c|c|}
\hline SEI component & Electrolyte & $\begin{array}{l}10^{\text {th }} \text { delithiation } \\
\left(\mu \mathrm{mol} / \mathrm{mg}_{\text {electrode }}\right)\end{array}$ & $\begin{array}{l}100^{\text {th }} \text { delithiation } \\
\left(\mu \mathrm{mol} / \mathrm{mg}_{\text {electrode }}\right)\end{array}$ \\
\hline \multirow{3}{*}{$\mathrm{LiF}$} & $3.2 \mathrm{~m} \mathrm{LiFSI}$ in $\mathrm{P}_{1222} \mathrm{FSI}$ & 3.5 & 5.5 \\
\hline & $3.2 \mathrm{~m} \mathrm{LiFSI}$ in $\mathrm{C}_{3} \mathrm{mpyrFSI}$ & 1.4 & 5.4 \\
\hline & LP $30+10 w t \%$ FEC & 5.1 & 10.3 \\
\hline \multirow{3}{*}{$\begin{array}{c}\text { Other lithiated } \\
\text { species }\end{array}$} & $3.2 \mathrm{~m} \mathrm{LiFSI}$ in $\mathrm{P}_{1222} \mathrm{FSI}$ & 1.0 & 5.9 \\
\hline & $3.2 \mathrm{~m} \mathrm{LiFSI}$ in $\mathrm{C}_{3} \mathrm{mpyrFSI}$ & 0.6 & --* \\
\hline & LP $30+10 w t \%$ FEC & 1.6 & --* \\
\hline
\end{tabular}

In addition to $\mathrm{LiF}$ and traces of other lithiated products, the signal arising at $-73 \mathrm{ppm}$ (Fig. S10 b) in ${ }^{19} \mathrm{~F}$ NMR is assigned to $\mathrm{PF}_{6}{ }^{-}$groups that correspond to dried or trapped $\mathrm{LiPF}_{6}$ [5], and possibly fluorophosphates. The ${ }^{31} \mathrm{P}$ NMR spectra (Fig. S10 c) validate the presence of these 
compounds, showing resonances at $-146 \mathrm{ppm}\left(\mathrm{PF}_{6}^{-}\right)$and at approximately $-18 \mathrm{ppm}$ (fluorophosphates containing groups such as $-\mathrm{PO}_{3} \mathrm{~F}^{2-}$ and $-\mathrm{PO}_{2} \mathrm{~F}_{2}{ }^{-}$).[66] As can be seen, these results highlight the stability of ILs and the susceptibility of classical electrolytes to degradation.

At this point, it is difficult to explain the different amounts of Li implicated in other lithiated species and in trapped LiFSI and why in some cases lithium is only present as LiF. The presence of all the elements constituting the IL cations in the SEI, as seen by STEM-EDX, suggests a structural contribution of IL cations or fragments of partially degraded IL cations to the SEI. Such complex architecture of the SEI could allow some LiFSI, for instance, to be trapped and be prevented from a further reaction with the reductive silicon surface. The inhomogenous distribution and the separation of F-rich areas and Si-rich areas, all containing elements constituting IL cations, supports the hypothesis that some distance may exist between areas rich in degradation products and the reductive surface of silicon. Such situation could help in trapping part of the lithiated species, including LiFSI or in hindering their further degradation reaction. In addition, from STEM-EDX, this separation between F-rich and Si-rich areas seems to be more pronounced in the case of the electrode cycled in the superconcentrated $\mathrm{P}_{1222}$-based system after 100 cycles. This would be consistent with the larger amount of lithiated species other than $\mathrm{LiF}$. Such nanostructuring near the silicon surface of IL cations and LiFSI and its corresponding fragments could then have an influence on the formation of such structure. Consequently, this impacts the amount of trapped lithiated species, including LiFSI, depending on the concentration (lithium and FSI amounts) and IL cations (stable $\mathrm{P}_{1222}{ }^{+}$or prone-to-degradation $\mathrm{C}_{3} \mathrm{mpyr}{ }^{+}$). In the next part, we try to further investigate the nanostructuring of the electrolyte components near the silicon surface that could help in understanding the formation of such different SEIs.

\subsection{Computational Investigation}


MD simulations were conducted to understand the interface structures of the two IL electrolytes and the effect from cation chemistry and LiFSI salt concentration. Since the classic MD simulation method does not involve any chemical reaction process, we should understand that the reported interfacial structures describe the interface before SEI formation and can be applied only to elucidate the early stages of cycling. The interfacial structure also closely affects the ion transport across the interface. Therefore, the cognition of such structure is of utmost importance for us to understand the battery performance.

We have studied a number of surface charge densities of $\pm 0.000, \pm 0.391, \pm 0.873$ and $\pm 1.461 \mathrm{e}$ $\mathrm{nm}^{-2}$ for the $\mathrm{C}_{3}$ mpyrFSI system at first, as the previous research showed that the surface charge (or applied voltage) could have an impact on interfacial structure and composition $[33,67,68]$ Essentially, the surface charge per area represents an excess of elemental charge ascribed to each surface atom of the Si electrode, which is related to the applied electrode electrostatic potential via Poisson equation [69], which was not calculated here. We simply evaluate the potential differences approximately based on the reference [29], which also reports the MD simulation of $\mathrm{C}_{3}$ mpyrFSI with the $20 \mathrm{~mol} \%$ (equivalent to $0.8 \mathrm{~m}$ ) of LiFSI salt near a graphite electrode using a similarly $10 \mathrm{~nm}$ long simulation box. The $4.2 \mathrm{~V}$ of voltage difference $(\Delta \mathrm{V})$ gives a surface charge density of around $4 \mu \mathrm{C} \mathrm{cm}^{-2}\left(0.25 \mathrm{e} \mathrm{nm}^{-2}\right)$ with a constant potential electrode model and polarizable force field. Although we cannot use the data in the reference to calculate the voltage difference corresponding to the charge density we use directly as the simulated electrode and MD methods are different, we can infer that the highest density we used here (i.e. $\pm 1.461 \mathrm{e} \mathrm{nm}^{-}$ ${ }^{2}$ ) should be used as an extreme condition for theoretical research purpose as it should exceed the practical voltage range $(>20 \Delta \mathrm{V})$. 
We firstly discuss the effect of the surface charge. From the number density profiles of $\mathrm{C}_{3}$ mpyrFSI-LiFSI given in Fig. S11, we have learned that, next to the uncharged electrode surface, both IL cations and anions coexist in the $0.8 \mathrm{~m}$ system (Fig. S11 d), while all ion species including $\mathrm{Li}^{+}$coexist in the $3.2 \mathrm{~m}$ system (Fig. 5e). When the negative surface charge was applied, both anions and $\mathrm{Li}^{+}$were pushed to the outer layer, resulting in a $\mathrm{C}_{3}$ mpyr ${ }^{+}$cationdominated inner-most layer. This was observed in both 0.8 and $3.2 \mathrm{~m}$ systems at the low to medium surface charge densities (Fig. S11 a-c and e-g), and the number of cations increases with the increase in surface charge density. The similar phenomenon was also seen in the reference [29] when comparing the number density profiles of $0 \mathrm{~V}$ and $4.2 \mathrm{~V}$ (Fig. S11 h). However, the Li ions appear again in the inner most layer at the extremely high surface charge density of \pm 1.461 $\mathrm{e} \mathrm{nm}^{-2}$ for the $0.8 \mathrm{~m}$ system or above the $\pm 0.873 \mathrm{e} \mathrm{nm}^{-2}$ for the $3.2 \mathrm{~m}$ system, in order to screen the high negative surface charge. But such a high surface charge density could be out of voltage limit in the real experiment as we discussed above.

Furthermore, we found that the number of ion layers is less dependent of surface charge, instead, the high salt concentration substantially reduces the number of interfacial layers for both ILs, which has been reported in our previous work for a concentrated $\mathrm{C}_{3} \mathrm{mpyrFSI} / \mathrm{NaFSI}$ system [33], and was also supported by a number of AFM studies [22,70]. The density profiles were compared between $\mathrm{P}_{1222} \mathrm{FSI}$ and $\mathrm{C}_{3}$ mpyrFSI with $0.8 \mathrm{~m}$ and $3.2 \mathrm{~m}$ of salt at $\pm 0.873 \mathrm{e} \mathrm{nm}^{-2}$ or uncharged surface in Fig 5. The dominated electrolyte component in the innermost layer near the negatively charged electrode (left side) is the IL cation for both salt concentrations (Fig. 5a-5d), and the first cation density peak is slightly higher for $\mathrm{C}_{3} \mathrm{mpyr}^{+}$, indicating that the number of $\mathrm{C}_{3}$ mpyr ${ }^{+}$cations exceeds that of $\mathrm{P}_{1222}{ }^{+}$. This is also consistent with the higher interaction energy (van der Waals + Coulombic energy) between cations in the innermost layer (within the cutoff of 
$1.2 \mathrm{~nm})$ and the electrode, as shown in Fig. $\mathrm{S} 12 \mathrm{a} . \mathrm{The} \mathrm{Li}^{+}$ions in the innermost layer $(<1 \mathrm{~nm}$ distance from the Si surface) are only found in the $3.2 \mathrm{~m} \mathrm{LiFSI}$ systems, but in a low population at a medium charge density of $-0.873 \mathrm{e} \mathrm{nm}^{-2}$. The second layer is dominated mainly by anions and Li ions or almost only by anions for the 3.2 and $0.8 \mathrm{~m}$ systems, respectively.

However, the differences in the number density profiles for all investigated concentrations and surface charge densities conditions are not significant between the two IL electrolytes. The above MD results alone cannot help to rationalize the difference in SEI compositions as discussed above and a further first-principle based analysis is necessary to attempt explaining some of these differences. For example, MAS NMR quantification shows that the $\mathrm{P}_{1222}$ system has more LiF products than the $\mathrm{C}_{3}$ mpyr system after 10 cycles. This can be understood by the LUMO orbital energy calculated on ion cluster structures that most likely appear in the innermost electrolyte layer. Since the LiF comes from Li-FSI reduction products that requires the coexistence of both Li and FSI in the innermost layer, we calculated ion complexes composed of one IL cation, one Li and two FSI anions (Fig. S12 b) as a reasonable representation of possible inner layer electrolyte structures. The lowest unoccupied molecular orbital (LUMO) orbital energy is always lower for the complex with $\mathrm{P}_{1222}{ }^{+}$than with the $\mathrm{C}_{3} \mathrm{mpyr}{ }^{+}$, indicating its lower reduction stability, consistent with a higher probability of reduction. We considered the complex with two types of Li-FSI coordination structures, i.e. mono-dentate and bi-dentate. Interestingly, when $\mathrm{Li}^{+}$coordinates to $\mathrm{FSI}^{-}$in a mono-dentate manner, the LUMO orbital distributes mainly on S-F bond of FSI ${ }^{-}$when $\mathrm{P}_{1222}$ is present, but it distributes throughout the majority of $\mathrm{FSI}^{-}$when $\mathrm{C}_{3}$ mpyr is present. This could indicate a more complete FSI decomposition in the presence of $\mathrm{C}_{3} \mathrm{mpyr}^{+}$as observed by MAS NMR after extended cycling, where only LiF is detected as SEI lithiated species. We also considered the influence of the IL cation which surrounds the Li-FSI 
complex and show that the fragmentation analysis indicates that more energy is needed to break the S-F and N-S bond in the presence of the $\mathrm{P}_{1222}{ }^{+}$cation compared to $\mathrm{C}_{3} \mathrm{mpyr}^{+}$(Table S4).

The overall trend that can be seen from the above calculations is in agreement with the MAS NMR results discussed above, indicating (i) that the $\mathrm{P}_{1222}$-based system leads to the formation of more LiF products than the $\mathrm{C}_{3}$ mpyr system early on in cycling and (ii) the possibility of complete LiFSI decomposition in the latter case leading to its end degradation product e.g. LiF, after 100 cycles. 
(a)

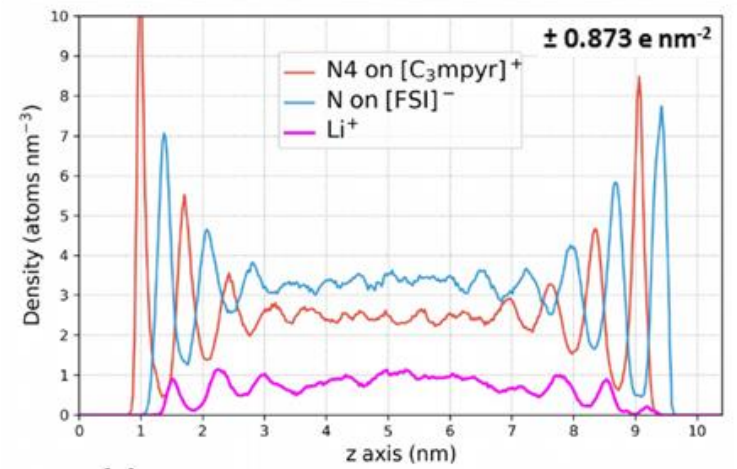

(c)

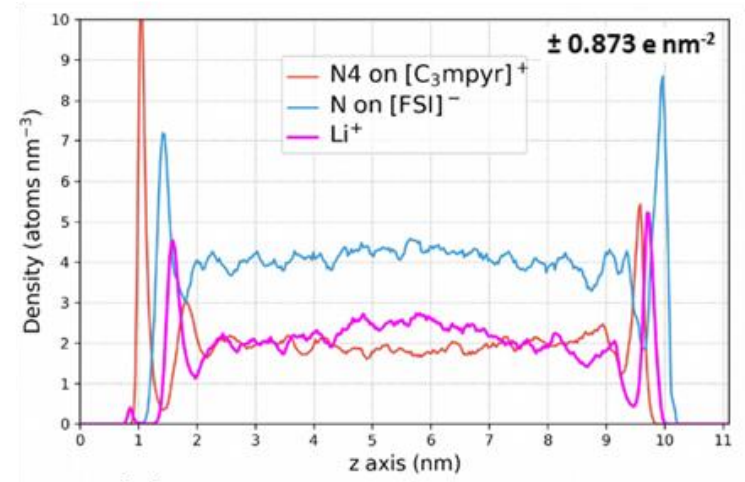

(e)

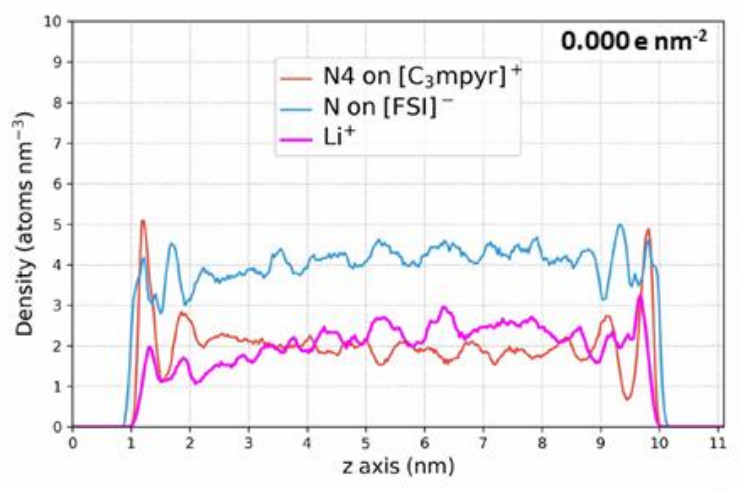

(b)

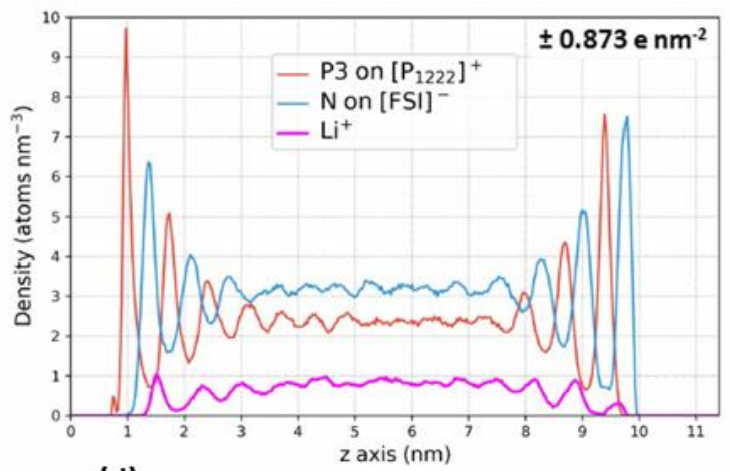

(d)

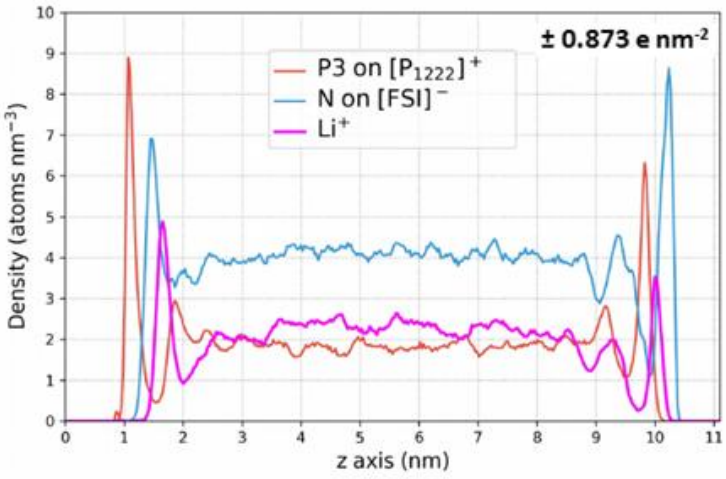

(f)

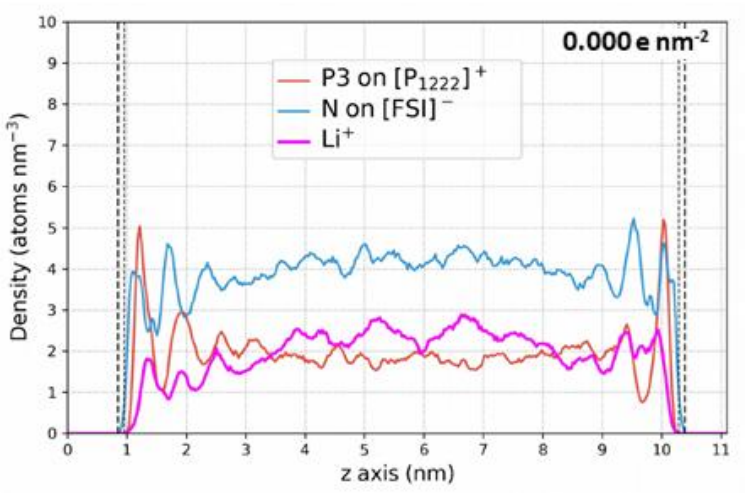

Figure 5. Partial density profile of $\mathrm{C}_{3}$ mpyrFSI and $\mathrm{P}_{1222} \mathrm{FSI}$ Ils with a-b) $0.8 \mathrm{~m} \mathrm{LiFSI}$, c-f) $3.2 \mathrm{~m}$ LiFSI at $\pm 0.873 \mathrm{e} \mathrm{nm}^{-2}$ and zero surface charge densities. Structural layers closer to the silicon negative electrode surface appear on the left side of the graphs while structural layers observed between 9 and $10 \mathrm{~nm}$ correspond to the lithium metal electrode side and are not commented in the present study.

\subsection{Differential Capacitance Measurements}


The DC measurements discussed in this section provides additional insights into the IL structure at the near-electrode surface. Whereas DC experiments are commonly applied to investigate energy storage in supercapacitors, we employ the same technique to gain a better understanding of the ion packing density near the electrode surface. Along with MD data, DC measurements provide essential information about the nanostructuring of the electrolyte components, which directly impacts the SEI formation and the early stages of cycling. All of the examined systems exhibit a U-like profile (Fig. 6) rather than the characteristic camel shape as predicted by mean field theory which describes the electric double layer behaviour of ILs. Nevertheless, a U-like profile is not unexpected particularly with glassy carbon electrodes.[28,29] Higher capacitance is observed at positive polarization in all cases. This region is associated with the stacking of the more symmetric FSI anions compared to $\mathrm{P}_{1222}{ }^{+}$or $\mathrm{C}_{3} \mathrm{mpyr}^{+}$. As the potential is decreased, the cations start to accumulate near the electrode which results in lower capacitance. With further decrease in potential towards more negative values, more cations are brought closer and are adsorbed on the electrode surface, thus increasing the capacitance again as a more compact layer of the positively charged species are formed. This behaviour is more prominent in the pyrrolidinium system regardless of the salt content. It seems that more negative potential is necessary to attract additional phosphonium cations to the electrode surface, suggesting that $\mathrm{P}_{1222}{ }^{+}$tends to be localized farther from the electrode surface compared to $\mathrm{C}_{3} \mathrm{mpyr}^{+}$. These observations can also be explained by crowding mechanism which refers to the accummulation of species of the same charge at the electrode surface. Based on DFT calculations (Table S5), the $\mathrm{C}_{3} \mathrm{mpyr}^{+}$cations have lower reductive stability compared to $\mathrm{P}_{1222}{ }^{+}$. Crowding is expected to occur at more negative potential values in the case of $\mathrm{P}_{1222}{ }^{+}$because of its larger electrochemical stability window or more precisely its less negative LUMO (-1.93 eV vs. $-1.98 \mathrm{eV}$ for $\left.\mathrm{C}_{3} \mathrm{mpyr}^{+}\right)$. 
In comparison with the neat systems, the ILs with LiFSI salt generally show higher capacitance which is more pronounced at higher polarization potentials. This is potentially due to the changes in ion packing density and effective electrode charge screening shown by MD simulations. Interestingly, the global capacitance of the electrolytes with $0.8 \mathrm{~m} \mathrm{LiFSI}$ is higher compared to those with $3.2 \mathrm{~m} \mathrm{LiFSI}$, with respect to the neat electrolytes. This might be due to two factors, namely, tighter ion packing at the innermost layer as well as changes in the composition of the outer layer upon Li doping that affects the overall length of electrode screening. These results are in line with the electrochemical behaviour of such systems (Fig. S1) where the dilute electrolytes exhibit drastic capacity loss after several cycles that is assigned to electrolyte degradation.[18] The higher packing density of these low salt electrolytes at the charged surface leaves them more susceptible to degradation as they interact with the strongly reducing Si surface. While such conclusions can be drawn from DC measurements, the amount of salt that is available is not as much as those in the superconcentrated systems. Hence, even when these salt anions break down, the amount of products is still less as reflected by their lower cell impedance (Fig. S9). Also, despite DC measurements showing the susceptibility of low salt systems to breakdown, it does not necessarily indicate that a complete decomposition will take place. As seen from MAS NMR, other lithiated species after 10 (and even after 100) cycles are still observed. 

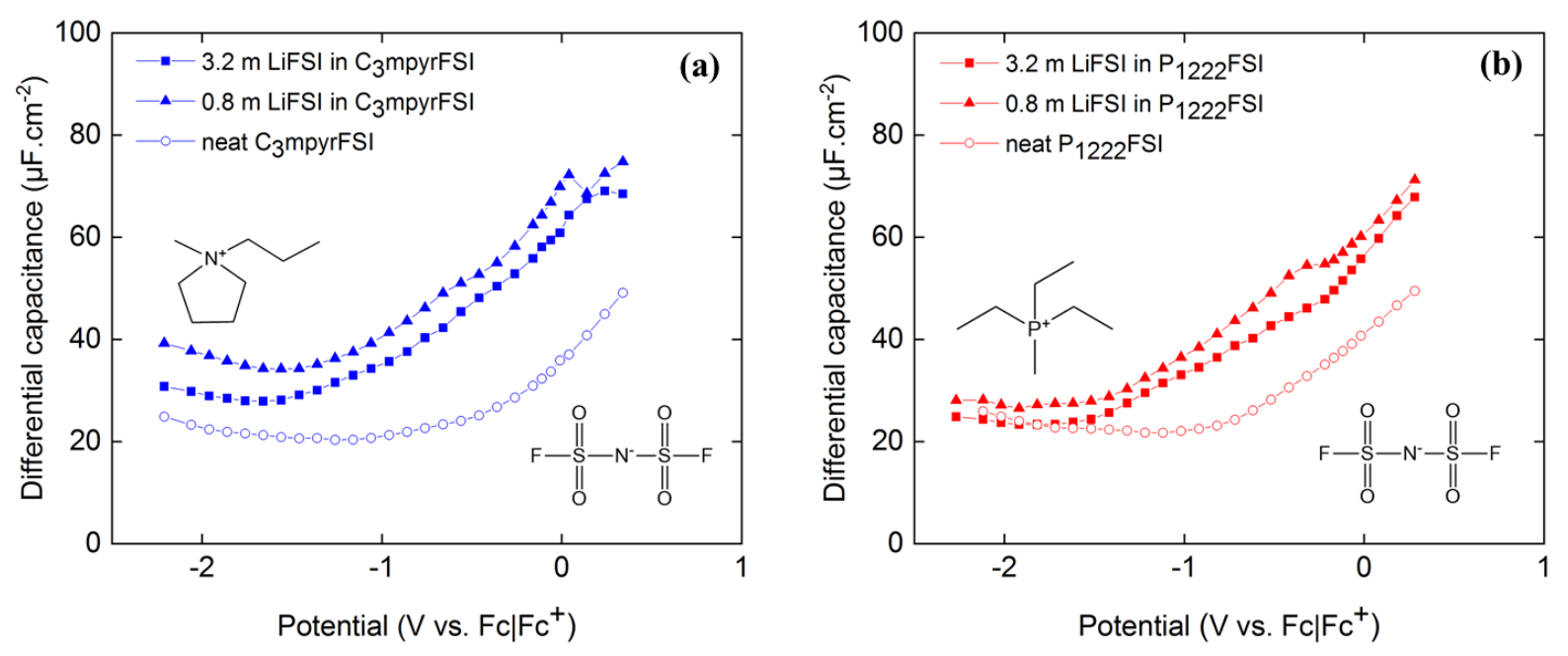

Figure 6. Differential capacitance curves of a) $\mathrm{C}_{3}$ mpyrFSI and b) $\mathrm{P}_{1222}$ FSI electrolytes with varying salt concentration measured at $55^{\circ} \mathrm{C}$ with a $\mathrm{GC}$ working electrode

Overall, our findings from the structural investigations support the reported electrochemical behaviour as well as conclusions from the SEI characterization. In the superconcentarted systems, MD simulations and DC experiments reveal a higher probability that the pyrrolidinium cations will participate in the SEI formation early on in cycling, compared to the phosphonium cations. First principle calculations further support this by indicating the lower stability of $\mathrm{C}_{3}$ mpyr $^{+}$based on LUMO values. Considering the FSI anions, the lower LUMO of the complexes containing $\mathrm{P}_{1222}{ }^{+}$indicate more breakdown products in this sytem, e.g. more LiF after 10 cycles from MAS NMR . Lastly, we have also seen from DC measurements the degradation susceptibility of the IL components in both electrolytes because of their higher density close to the surface.

\section{Conclusion}

A combination of experimental and computational methods was carried out to unveil the impact of IL cation nature and salt concentration on the interfacial structure of a Si electrode and the SEI 
formed upon polarization. Our findings highlight that superconcentrated $\mathrm{P}_{1222}$ FSI-LiFSI results in an electrode/electrolyte interface that favours superior electrochemical performance. Ex situ characterization techniques such as SEM, STEM-EDX, and MAS NMR reveal an intact electrode after extended cycling in $\mathrm{P}_{1222} \mathrm{FSI}$ with $3.2 \mathrm{~m} \mathrm{LiFSI}$, with an SEI comprised mainly of $\mathrm{LiF}$ and other lithiated products, including degradation products stemming from the decomposition of LiFSI as well as trapped LiFSI salt. Such SEI provides a better pathway for effective electrochemistry as opposed to the case of the superconcentrated $\mathrm{C}_{3}$ mpyrFSI-LiFSI electrolyte, where a more blocking SEI seems to form after an extended cycling, containing LiF as the sole lithiated product. This seemingly more efficient and less resistive SEI, combined with the higher stability of the superconcentrated $\mathrm{P}_{1222}$-based electrolyte highlighted in our previous work [18] can explain the outstanding performance of this electrolyte with silicon electrodes. In parallel, for both $\mathrm{P}_{1222}$-based and $\mathrm{C}_{3}$ mpyr-based dilute systems, non-blocking SEIs containing a favorable mix of $\mathrm{LiF}$ and other lithiated products are formed. The lower electrochemical performance obtained for these systems can be then explained by the degradation of bulk electrolyte, as also shown in our previous work.[18]

Through MD simulations, we found that $\mathrm{C}_{3} \mathrm{mpyr}^{+}$cations have stronger interaction with the $\mathrm{Si}$ compared to $\mathrm{P}_{1222}{ }^{+}$. This near-electrode electrolyte nanostructuring, valid for the early stages of cycling, is supported by $\mathrm{DC}$ measurements, showing that $\mathrm{C}_{3}$ mpyrFSI possesses higher ion packing density close to the negatively charged electrode. Both MD and DC data also reveal the increased accumulation of IL cations at the interphase region in dilute electrolytes compared to superconcentrated systems. These findings provided valuable insights into the decomposition pathway of the electrolyte components, which support the obtained information from SEI characterization and the reported electrochemical behaviour. 
Identifying causes leading to different degradation pathway yielding either SEI containing only $\mathrm{LiF}$ or SEI containing an appropriate mix of $\mathrm{LiF}$ and other lithiated species will allow for a rational design of functional $\mathrm{Si}$-based $\mathrm{Li}$-ion batteries. The modelling and MD simulation that we performed in order to study the structuration of the electrolyte nearby the surface of the electrodes provides nevertheless valuable information about the starting point of the decomposition pathway of the electrolyte components: such MD simulation is done considering a "neat" or model electrode surface that can be seen as the electrode surface before any SEI accumulation. It would be interesting to develop such calculations including an evolution of the surface due to the presence of SEI. Overall, this work will greatly benefit the further understanding of SEI formation on Si anodes, thus enabling rational design of future Si-based LIBs. Furthermore, the effect of other electrolyte constituents, e.g., anion and additives, should also be explored in the same context.

\section{AUTHOR INFORMATION}

\section{Corresponding Author}

*E-mail: nicolas-dupre@ cnrs-imn.fr (N.D.).

\section{Author Contributions}

Khryslyn Araño (K.A.) : experimental investigation, data analysis, manuscript writing, editing and revision. Srdan Begić (S.B.): computational experiments. Fangfang Chen (F.C.): analysis and drafting of the computational section. Dmitrii Rakov (D.R.): scientific discussion and computational section analysis. Driss Mazouzi (D.M.): scientific discussion, help with electrodes preparation, SEM imaging. Nicolas Gautier (N.G.): TEM experiments. Robert Kerr (R.K.): 
scientific discussion, manuscript editing. Bernard Lestriez (B.L.): project conception, scientific discussion, manuscript editing. Jean Le Bideau (J.LB): project conception, scientific discussion, manuscript editing. Patrick C. Howlett (P.C.H.): project conception, scientific discussion, manuscript editing. Dominique Guyomard (D.G.): project conception, scientific discussion, manuscript editing and revision. Maria Forsyth (M.F.): project conception, scientific discussion, manuscript editing. Nicolas Dupré (N.D.): project conception, scientific discussion, MAS-NMR experiments and data analysis, TEM sample preparation, manuscript editing and revision.

\section{ORCID}

Nicolas Dupré : 0000-0002-0687-9357

Maria Forsyth : 0000-0002-4273-8105

Patrick C. Howlett : 0000-0002-2151-2932

Bernard Lestriez : 0000-0002-6579-5516

Robert Kerr : 0000-0001-7499-3920

\section{Notes}

The authors declare no competing financial interest.

\section{ACKNOWLEDGMENTS}

K. A. received funding from the French Agence de l'Environnement et de la Maîtrise de l’Énergie (ADEME) and Deakin University. Contract N TEZ17-03.

S.B., F.C., D.R., R.K., P.C.H. and M.F. also acknowledge the Australian Research Council Centre of Excellence for Electromaterials Science through grant CE140100012. 


\section{REFERENCES}

[1] J.M. Tarascon, M. Armand, Issues and Challenges Facing Rechargeable Lithium Batteries, Mater. Sustain. Energy A Collect. Peer-Reviewed Res. Rev. Artic. from Nat. Publ. Gr. 414 (2010) 171-179. https://doi.org/10.1142/9789814317665_0024.

[2] J.B. Goodenough, K.S. Park, The Li-Ion Rechargeable Battery: A Perspective, J. Am. Chem. Soc. 135 (2013) 1167-1176. https://doi.org/10.1021/ja3091438.

[3] J. Lu, Z. Chen, F. Pan, Y. Cui, K. Amine, High-Performance Anode Materials for Rechargeable Lithium-Ion Batteries, Electrochem. Energy Rev. 1 (2018) 35-53. https://doi.org/10.1007/s41918-018-0001-4.

[4] M.N. Obrovac, L.J. Krause, Reversible Cycling of Crystalline Silicon Powder, J. Electrochem. Soc. 154 (2007) A103-A108. https://doi.org/10.1149/1.2402112.

[5] N. Dupré, P. Moreau, E. De Vito, L. Quazuguel, M. Boniface, A. Bordes, C. Rudisch, P. Bayle-Guillemaud, D. Guyomard, Multiprobe Study of the Solid Electrolyte Interphase on Silicon-Based Electrodes in Full-Cell Configuration, Chem. Mater. 28 (2016) 2557-2572. https://doi.org/10.1021/acs.chemmater.5b04461.

[6] Z. Karkar, D. Mazouzi, C.R. Hernandez, D. Guyomard, L. Roué, B. Lestriez, ThresholdLike Dependence of Silicon-Based Electrode Performance on Active Mass Loading and Nature of Carbon Conductive Additive, Electrochim. Acta. 215 (2016) 276-288. https://doi.org/10.1016/j.electacta.2016.08.118.

[7] U. Kasavajjula, C. Wang, A.J. Appleby, Nano- and Bulk-Silicon-Based Insertion Anodes for Lithium-Ion Secondary Cells, J. Power Sources. 163 (2007) 1003-1039. 
https://doi.org/10.1016/j.jpowsour.2006.09.084.

[8] D. Mazouzi, N. Delpuech, Y. Oumellal, M. Gauthier, M. Cerbelaud, J. Gaubicher, N. Dupré, P. Moreau, D. Guyomard, L. Roué, B. Lestriez, New Insights Into the SiliconBased Electrode's Irreversibility Along Cycle Life Through Simple Gravimetric Method, J. Power Sources. 220 (2012) 180-184. https://doi.org/10.1016/j.jpowsour.2012.08.007.

[9] H. Wu, Y. Cui, Designing Nanostructured Si Anodes for High Energy Lithium Ion Batteries, Nano Today. 7 (2012) 414-429. https://doi.org/10.1016/j.nantod.2012.08.004.

[10] D. Mazouzi, B. Lestriez, L. Roué, D. Guyomard, Silicon Composite Electrode with High Capacity and Long Cycle Life, Electrochem. Solid-State Lett. 12 (2009) A215-A218. https://doi.org/10.1149/1.3212894.

[11] N.S. Choi, K.H. Yew, K.Y. Lee, M. Sung, H. Kim, S.S. Kim, Effect of Fluoroethylene Carbonate Additive on Interfacial Properties of Silicon Thin-Film Electrode, J. Power Sources. 161 (2006) 1254-1259. https://doi.org/10.1016/j.jpowsour.2006.05.049.

[12] J.S. Kim, D. Byun, J.K. Lee, Electrochemical Characteristics of Amorphous Silicon Thin Film Electrode with Fluoroethylene Carbonate Additive, Curr. Appl. Phys. 14 (2014) 596-602. https://doi.org/10.1016/j.cap.2014.02.008.

[13] C. Li, J. Maier, Ionic Space Charge Effects in Lithium Fluoride Thin Films, Solid State Ionics. 225 (2012) 408-411. https://doi.org/10.1016/j.ssi.2012.02.036.

[14] F. Chen, M. Forsyth, Elucidation of Transport Mechanism and Enhanced Alkali Ion Transference Numbers in Mixed Alkali Metal-Organic Ionic Molten Salts, Phys. Chem. Chem. Phys. 18 (2016) 19336-19344. https://doi.org/10.1039/c6cp01411a. 
[15] Q. Zhou, W.A. Henderson, G.B. Appetecchi, M. Montanino, S. Passerini, Physical and Electrochemical Properties of N-alkyl-N-methylpyrrolidinium Bis(fluorosulfonyl)imide Ionic Liquids: PY ${ }_{13}$ FSI and PY ${ }_{14}$ FSI, J. Phys. Chem. B. 112 (2008) 13577-13580. https://doi.org/10.1021/jp805419f.

[16] M. Watanabe, M.L. Thomas, S. Zhang, K. Ueno, T. Yasuda, K. Dokko, Application of Ionic Liquids to Energy Storage and Conversion Materials and Devices, Chem. Rev. 117 (2017) 7190-7239. https://doi.org/10.1021/acs.chemrev.6b00504.

[17] Y. Domi, H. Usui, K. Yamaguchi, S. Yodoya, H. Sakaguchi, Silicon-Based Anodes with Long Cycle Life for Lithium-Ion Batteries Achieved by Significant Suppression of Their Volume Expansion in Ionic-Liquid Electrolyte, ACS Appl. Mater. Interfaces. 11 (2019) 2950-2960. https://doi.org/10.1021/acsami.8b17123.

[18] K. Araño, D. Mazouzi, R. Kerr, B. Lestriez, J. Le Bideau, P.C. Howlett, N. Dupré, M. Forsyth, D. Guyomard, Editors' Choice—Understanding the Superior Cycling Performance of Si Anode in Highly Concentrated Phosphonium-Based Ionic Liquid Electrolyte, J. Electrochem. Soc. 167 (2020) 120520-120530. https://doi.org/10.1149/1945-7111/abac84.

[19] M. Nie, D.P. Abraham, Y. Chen, A. Bose, B.L. Lucht, Silicon Solid electrolyte Interphase (SEI) of Lithium Ion Battery Characterized by Microscopy and Spectroscopy, J. Phys. Chem. C. 117 (2013) 13403-13412. https://doi.org/10.1021/jp404155y.

[20] N. Delpuech, N. Dupre, P. Moreau, J.S. Bridel, J. Gaubicher, B. Lestriez, D. Guyomard, Mechanism of Silicon Electrode Aging Upon Cycling in Full Lithium-Ion Batteries, ChemSusChem. 9 (2016) 841-848. https://doi.org/10.1002/cssc.201501628. 
[21] G.M.A. Girard, M. Hilder, N. Dupre, D. Guyomard, D. Nucciarone, K. Whitbread, S. Zavorine, M. Moser, M. Forsyth, D.R. MacFarlane, P.C. Howlett, Spectroscopic Characterization of the SEI Layer Formed on Lithium Metal Electrodes in Phosphonium Bis(fluorosulfonyl)imide Ionic Liquid Electrolytes, ACS Appl. Mater. Interfaces. 10 (2018) 6719-6729. https://doi.org/10.1021/acsami.7b18183.

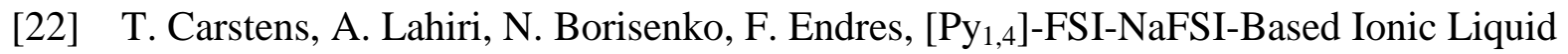
Electrolyte for Sodium Batteries: $\mathrm{Na}^{+}$Solvation and Interfacial Nanostructure on $\mathrm{Au}(111)$, J. Phys. Chem. C. 120 (2016) 14736-14741. https://doi.org/10.1021/acs.jpcc.6b04729.

[23] D. Lu, J. Tao, P. Yan, W.A. Henderson, Q. Li, Y. Shao, M.L. Helm, O. Borodin, G.L. Graff, B. Polzin, C.M. Wang, M. Engelhard, J.G. Zhang, J.J. De Yoreo, J. Liu, J. Xiao, Formation of Reversible Solid Electrolyte Interface on Graphite Surface from Concentrated Electrolytes, Nano Lett. 17 (2017) 1602-1609. https://doi.org/10.1021/acs.nanolett.6b04766.

[24] Y. Lauw, M.D. Horne, T. Rodopoulos, V. Lockett, B. Akgun, W.A. Hamilton, A.R.J. Nelson, Structure of $\left[\mathrm{C}_{4} \mathrm{mpyr}\right]\left[\mathrm{NTf}_{2}\right]$ Room-Temperature Ionic Liquid at Charged Gold Interfaces, Langmuir. 28 (2012) 7374-7381. https://doi.org/10.1021/la3005757.

[25] K. Akutsu-Suyama, M. Cagnes, K. Tamura, T. Kanaya, T.A. Darwish, Controlled Deuterium Labelling of Imidazolium Ionic Liquids to Probe the Fine Structure of the Electrical Double Layer using Neutron Reflectometry, Phys. Chem. Chem. Phys. 21 (2019) 17512-17516. https://doi.org/10.1039/c9cp02479d.

[26] S. Baldelli, Surface Structure at the Ionic Liquid-Electrified Metal Interface, Acc. Chem. Res. 41 (2008) 421-431. https://doi.org/10.1021/ar700185h. 
[27] K. Motobayashi, Y. Shibamura, K. Ikeda, Potential-Induced Interfacial Restructuring of a Pyrrolidinium-Based Ionic Liquid on an Au Electrode: Effect of Polarization of Constituent ions, Electrochem. Commun. 100 (2019) 117-120.

https://doi.org/10.1016/j.elecom.2019.02.003.

[28] M.M. Islam, M.T. Alam, T. Ohsaka, Electrical Double-layer Structure in Ionic Liquids: A Corroboration of the Theoretical Model by Experimental Results, J. Phys. Chem. C. 112 (2008) 16568-16574. https://doi.org/10.1021/jp8058849.

[29] J.B. Haskins, J.J. Wu, J.W. Lawson, Computational and Experimental Study of Li-Doped Ionic Liquids at Electrified Interfaces, J. Phys. Chem. C. 120 (2016) 11993-12011. https://doi.org/10.1021/acs.jpcc.6b02449.

[30] M. Jitvisate, J.R.T. Seddon, Direct Measurement of the Differential Capacitance of Solvent-Free and Dilute Ionic Liquids, J. Phys. Chem. Lett. 9 (2018) 126-131. https://doi.org/10.1021/acs.jpclett.7b02946.

[31] L.E. Camacho-Forero, T.W. Smith, P.B. Balbuena, Effects of High and Low Salt Concentration in Electrolytes at Lithium-Metal Anode Surfaces, J. Phys. Chem. C. 121 (2017) 182-194. https://doi.org/10.1021/acs.jpcc.6b10774.

[32] N. Takenaka, T. Fujie, A. Bouibes, Y. Yamada, A. Yamada, M. Nagaoka, Microscopic Formation Mechanism of Solid Electrolyte Interphase Film in Lithium-Ion Batteries with Highly Concentrated Electrolyte, J. Phys. Chem. C. 122 (2018) 2564-2571. https://doi.org/10.1021/acs.jpcc.7b11650.

[33] D.A. Rakov, F. Chen, S.A. Ferdousi, H. Li, T. Pathirana, A. Simonov, P.C. Howlett, R. Atkin, M. Forsyth, Engineering High Energy Density Sodium Battery Anodes for 
Improved Cycling with Superconcentrated Ionic Liquid Electrolytes, Nat. Mater. 19 (2020) 1096-1101. https://doi.org/10.1038/s41563-020-0673-0.

[34] B.P.N. Nguyen, J. Gaubicher, B. Lestriez, Analogy Between Electrochemical Behaviour of Thick Silicon Granular Electrodes for Lithium Batteries and Fine Soils Micromechanics, Electrochim. Acta. 120 (2014) 319-326. https://doi.org/10.1016/j.electacta.2013.12.126.

[35] B.P.N. Nguyen, S. Chazelle, M. Cerbelaud, W. Porcher, B. Lestriez, Manufacturing of Industry-relevant Silicon Negative Composite Electrodes for Lithium ion-cells, J. Power Sources. 262 (2014) 112-122. https://doi.org/10.1016/j.jpowsour.2014.03.119.

[36] H. Yoon, P.C. Howlett, A.S. Best, M. Forsyth, D.R. MacFarlane, Fast Charge/Discharge of Li Metal Batteries Using an Ionic Liquid Electrolyte, J. Electrochem. Soc. 160 (2013) A1629-A1637. https://doi.org/10.1149/2.022310jes.

[37] R. Kerr, D. Mazouzi, M. Eftekharnia, B. Lestriez, N. Dupré, M. Forsyth, D. Guyomard, P.C. Howlett, High-Capacity Retention of Si Anodes Using a Mixed Lithium/Phosphonium Bis(fluorosulfonyl)imide Ionic Liquid Electrolyte, ACS Energy Lett. 2 (2017) 1804-1809. https://doi.org/10.1021/acsenergylett.7b00403.

[38] M. Cuisinier, J.F. Martin, P. Moreau, T. Epicier, R. Kanno, D. Guyomard, N. Dupré, Quantitative MAS NMR Characterization of the $\mathrm{LiMn}_{1 / 2} \mathrm{Ni}_{1 / 2} \mathrm{O}_{2}$ Electrode/Electrolyte Interphase, Solid State Nucl. Magn. Reson. 42 (2012) 51-61. https://doi.org/10.1016/j.ssnmr.2011.09.001.

[39] D. Massiot, F. Fayon, M. Capron, I. King, S. Le Calvé, B. Alonso, J.O. Durand, B. Bujoli, Z. Gan, G. Hoatson, Modelling One- and Two-Dimensional Solid-State NMR Spectra, 
Magn. Reson. Chem. 40 (2002) 70-76. https://doi.org/10.1002/mrc.984.

[40] D. Massiot, https://nmr.cemhti.cnrs-orleans.fr/dmfit/.

[41] J.M. Klein, E. Panichi, B. Gurkan, Potential Dependent Capacitance of [EMIM][TFSI], [N $\left.\mathrm{N}_{114}\right][\mathrm{TFSI}]$ and [PYR 13$][\mathrm{TFSI}]$ Ionic Liquids on Glassy Carbon, Phys. Chem. Chem. Phys. 21 (2019) 3712-3720. https://doi.org/10.1039/c8cp04631j.

[42] X.H. Liu, L. Zhong, S. Huang, S.X. Mao, T. Zhu, J.Y. Huang, Size-Dependent Fracture of Silicon Nanoparticles During Lithiation, ACS Nano. 6 (2012) 1522-1531. https://doi.org/10.1021/nn204476h.

[43] Y. Domi, H. Usui, R. Takaishi, H. Sakaguchi, Lithiation and Delithiation Reactions of Binary Silicide Electrodes in an Ionic Liquid Electrolyte as Novel Anodes for Lithium-Ion Batteries, ChemElectroChem. 6 (2019) 581-589. https://doi.org/10.1002/celc.201801088.

[44] S. Yodoya, Y. Domi, H. Usui, H. Sakaguchi, Applicability of an Ionic Liquid Electrolyte to a Phosphorus-Doped Silicon Negative Electrode for Lithium-Ion Batteries, ChemistrySelect. 4 (2019) 1375-1378. https://doi.org/10.1002/slct.201803282.

[45] H. Shobukawa, J. Shin, J. Alvarado, C.S. Rustomji, Y.S. Meng, Electrochemical Reaction and Surface Chemistry for Performance Enhancement of a Si Composite Anode Using a Bis(fluorosulfonyl)imide-based Ionic Liquid, J. Mater. Chem. A. 4 (2016) 15117-15125. https://doi.org/10.1039/c6ta06447g.

[46] G.M.A. Girard, M. Hilder, D. Nucciarone, K. Whitbread, S. Zavorine, M. Moser, M. Forsyth, D.R. MacFarlane, P.C. Howlett, Role of Li Concentration and the SEI Layer in Enabling High Performance Li Metal Electrodes using a Phosphonium 
Bis(fluorosulfonyl)imide Ionic Liquid, J. Phys. Chem. C. 121 (2017) 21087-21095. https://doi.org/10.1021/acs.jpcc.7b01929.

[47] E. Peled, S. Menkin, Review—SEI: Past, Present and Future, J. Electrochem. Soc. 164 (2017) A1703-A1719. https://doi.org/10.1149/2.1441707jes.

[48] Y. Preibisch, F. Horsthemke, M. Winter, S. Nowak, A.S. Best, Is the Cation Innocent? An Analytical Approach on the Cationic Decomposition Behavior of N-Butyl- Nmethylpyrrolidinium Bis(trifluoromethanesulfonyl)imide in Contact with Lithium Metal, Chem. Mater. 32 (2020) 2389-2398. https://doi.org/10.1021/acs.chemmater.9b04827.

[49] N. Delpuech, N. Dupré, D. Mazouzi, J. Gaubicher, P. Moreau, J.S. Bridel, D. Guyomard, B. Lestriez, Correlation Between Irreversible Capacity and Electrolyte Solvents Degradation Probed by NMR in Si-Based Negative Electrode of Li-Ion Cell, Electrochem. Commun. 33 (2013) 72-75. https://doi.org/10.1016/j.elecom.2013.05.001.

[50] Y. Oumellal, N. Delpuech, D. Mazouzi, N. Dupré, J. Gaubicher, P. Moreau, P. Soudan, B. Lestriez, D. Guyomard, The Failure Mechanism of Nano-Sized Si-Based Negative Electrodes for Lithium Ion Batteries, J. Mater. Chem. 21 (2011) 6201-6208. https://doi.org/10.1039/c1jm10213c.

[51] B. Key, R. Bhattacharyya, M. Morcrette, V. Seznéc, J.M. Tarascon, C.P. Grey, Real-Time NMR Investigations of Structural Changes in Silicon Electrodes for Lithium-Ion Batteries, J. Am. Chem. Soc. 131 (2009) 9239-9249. https://doi.org/10.1021/ja8086278.

[52] B.M. Meyer, N. Leifer, S. Sakamoto, S.G. Greenbaum, C.P. Grey, High Field Nultinuclear NMR Investigation of the SEI Layer in Lithium Rechargeable Batteries, Electrochem. Solid-State Lett. 8 (2005) 5-9. https://doi.org/10.1149/1.1854117. 
[53] K.A. See, M. Leskes, J.M. Griffin, S. Britto, P.D. Matthews, A. Emly, A. Van Der Ven, D.S. Wright, A.J. Morris, C.P. Grey, R. Seshadri, Ab Initio Structure Search and In Situ ${ }^{7}$ Li NMR Studies of Discharge Products in the Li-S Battery System, J. Am. Chem. Soc. 136 (2014) 16368-16377. https://doi.org/10.1021/ja508982p.

[54] A. Mousavi, A. Bensalem, B. Gee, Low-Temperature Synthesis of a Green Material for Lithium-Ion Batteries Cathode, Green Chem. Lett. Rev. 3 (2010) 135-142. https://doi.org/10.1080/17518251003619184.

[55] E. Lataste, C. Legein, M. Body, J.Y. Buzaré, A. Tressaud, A. Demourgues, Highly Fluorinated Silica Obtained by Direct $\mathrm{F}_{2}$-Gas Fluorination: Stability and Unprecedented Fluorosilicate Species Revealed by Solid State NMR Investigation, J. Phys. Chem. C. 113 (2009) 18652-18660. https://doi.org/10.1021/jp9087628.

[56] A. Basile, A.I. Bhatt, A.P. O’Mullane, Stabilizing Lithium Metal Using Ionic Liquids for Long-Lived Batteries, Nat. Commun. 7 (2016) 1-11. https://doi.org/10.1038/ncomms11794.

[57] R.K. Harris, T. V. Thompson, P.R. Norman, C. Pottage, Phosphorus-31 NMR Studies of Adsorption Onto Activated Carbon, Carbon N. Y. 37 (1999) 1425-1430. https://doi.org/10.1016/S0008-6223(99)00004-4.

[58] A.C. Forse, J.M. Griffin, H. Wang, N.M. Trease, V. Presser, Y. Gogotsi, P. Simon, C.P. Grey, Nuclear Magnetic Resonance Study of Ion Adsorption on Microporous CarbideDerived Carbon, Phys. Chem. Chem. Phys. 15 (2013) 7722-7730. https://doi.org/10.1039/c3cp51210j.

[59] L.M. Scherf, A.J. Karttunen, O. Pecher, P.C.M.M. Magusin, C.P. Grey, T.F. Fässler, 
[Ge2](4-) Dumbbells with Very Short Ge-Ge Distances in the Zintl Phase Li3NaGe2: A Solid-State Equivalent to Molecular O2, Angew. Chemie - Int. Ed. 55 (2016) 1075-1079. https://doi.org/10.1002/anie.201508044.

[60] J. Xiong, N. Dupre, D. Mazouzi, D. Guyomard, L. Roué, B. Lestriez, Influence of the polyacrylic acid binder neutralization degree on the initial electrochemical behavior of a silicon / graphite electrode, ACS Appl. Mater. Interfaces. (2021) Accepted.

[61] S.A. Ferdousi, L.A. O'Dell, M. Hilder, A.J. Barlow, M. Armand, M. Forsyth, P.C. Howlett, SEI Formation on Sodium Metal Electrodes in Superconcentrated Ionic Liquid Electrolytes and the Effect of Additive Water, ACS Appl. Mater. Interfaces. 13 (2021) 5706-5720. https://doi.org/10.1021/acsami.0c18119.

[62] A.M. Haregewoin, A.S. Wotango, B.J. Hwang, Electrolyte Additives for Lithium Ion Battery Electrodes: Progress and Perspectives, Energy Environ. Sci. 9 (2016) 1955-1988. https://doi.org/10.1039/c6ee00123h.

[63] T. Jaumann, J. Balach, U. Langklotz, V. Sauchuk, M. Fritsch, A. Michaelis, V. Teltevskij, D. Mikhailova, S. Oswald, M. Klose, G. Stephani, R. Hauser, J. Eckert, L. Giebeler, Lifetime vs. Rate Capability: Understanding the Role of FEC and VC in High-Energy Liion Batteries with Nano-Silicon Anodes, Energy Storage Mater. 6 (2017) 26-35. https://doi.org/10.1016/j.ensm.2016.08.002.

[64] K. Tasaki, A. Goldberg, J.-J. Lian, M. Walker, A. Timmons, S.J. Harris, Solubility of Lithium Salts Formed on the Lithium-Ion Battery Negative Electrode Surface in Organic Solvents, J. Electrochem. Soc. 156 (2009) A1019-A1027. https://doi.org/10.1149/1.3239850. 
[65] H. Yildirim, A. Kinaci, M.K.Y. Chan, J.P. Greeley, First-Principles Analysis of Defect Thermodynamics and Ion Transport in Inorganic SEI Compounds: LiF and NaF, ACS Appl. Mater. Interfaces. 7 (2015) 18985-18996. https://doi.org/10.1021/acsami.5b02904.

[66] A. V. Plakhotnyk, L. Ernst, R. Schmutzler, Hydrolysis in the System LiPF 6 - Propylene Carbonate - Dimethyl Carbonate - $\mathrm{H}_{2} \mathrm{O}$, J. Fluor. Chem. 126 (2005) 27-31. https://doi.org/10.1016/j.jfluchem.2004.09.027.

[67] K. Kirchner, T. Kirchner, V. Ivaništšev, M. V. Fedorov, Electrical Double Layer in Ionic Liquids: Structural Transitions from Multilayer to Monolayer Structure at the Interface, Electrochim. Acta. 110 (2013) 762-771. https://doi.org/10.1016/j.electacta.2013.05.049.

[68] O. Borodin, X. Ren, J. Vatamanu, A. Von Wald Cresce, J. Knap, K. Xu, Modeling Insight Into Battery Electrolyte Electrochemical Stability and Interfacial Structure, Acc. Chem. Res. 50 (2017) 2886-2894. https://doi.org/10.1021/acs.accounts.7b00486.

[69] J. Vatamanu, L. Xing, W. Li, D. Bedrov, Influence of Temperature on the Capacitance of Ionic Liquid Electrolytes on Charged Surfaces, Phys. Chem. Chem. Phys. 16 (2014) 5174-5182. https://doi.org/10.1039/c3cp54705a.

[70] V. Hoffmann, G. Pulletikurthi, T. Carstens, A. Lahiri, A. Borodin, M. Schammer, B. Horstmann, A. Latz, F. Endres, Influence of a Silver Salt on the Nanostructure of a $\mathrm{Au}(111) /$ Ionic Liquid Interface: An Atomic Force Microscopy Study and Theoretical Concepts, Phys. Chem. Chem. Phys. 20 (2018) 4760-4771. https://doi.org/10.1039/c7cp08243f. 
TOC graphics

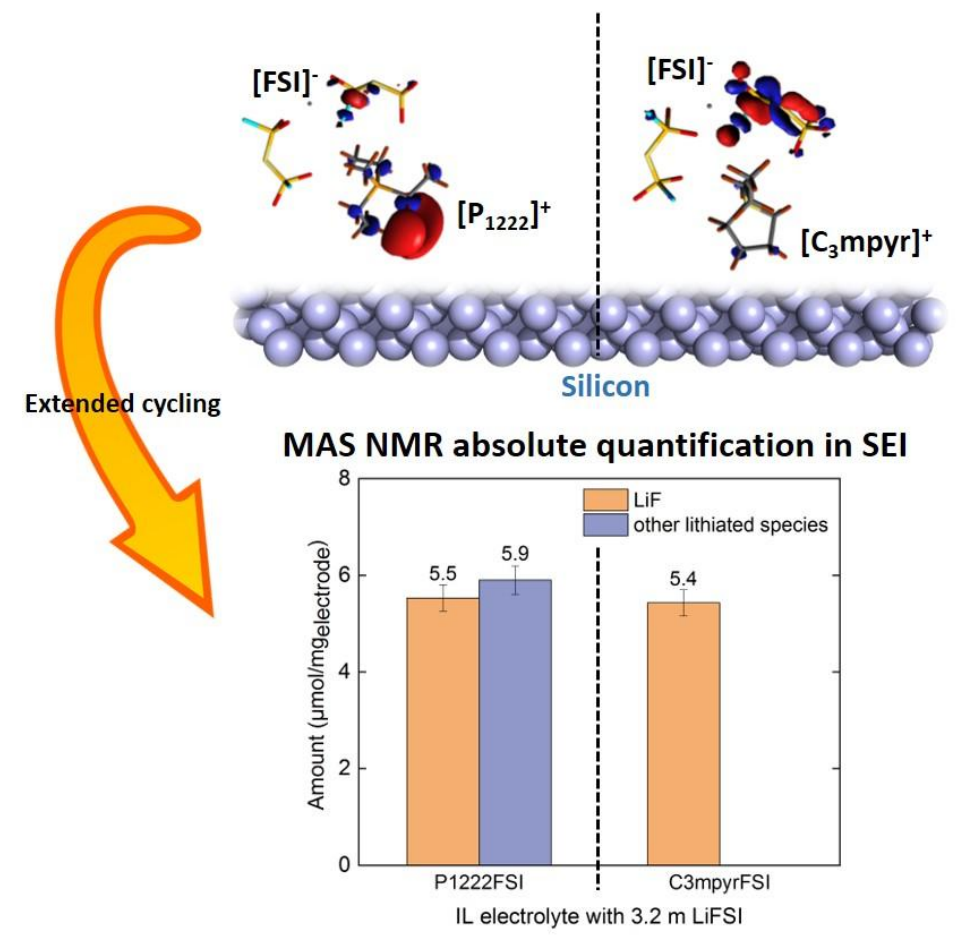

